THE SPENCE BAY PROJECT:

\title{
INUIT REPRESENTATION, SOCIAL ENGAGEMENT, AND FEMINIST PEDAGOGY IN THE PHOTOGRAPHIC WORK OF PAMELA HARRIS
}

\author{
by \\ Liisa Graham \\ B.F.A. Photography, Ryerson University, Toronto, 2004 \\ A thesis \\ presented to Ryerson University, Toronto, Ontario, Canada \\ in partial fulfillment of the \\ requirements for the degree of
}

\section{Master of Arts}

in the Program of

Film and Photography Preservation and Collections Management

Toronto, Ontario, Canada, 2015

(C) Liisa Graham 2015 


\section{AUTHOR'S DECLARATION FOR ELECTRONIC SUBMISSION OF A THESIS}

I hereby declare that I am the sole author of this thesis. This is a true copy of the thesis, including any required final revisions, as accepted by my examiners.

I authorize Ryerson University to lend this thesis to other institutions or individuals for the purpose of scholarly research.

I further authorize Ryerson University to reproduce this thesis by photocopying or by other means, in total or in part, at the request of other institutions or individuals for the purpose of scholarly research.

I understand that my thesis may be made electronically available to the public. 
The Spence Bay Project: Inuit Representation, Social Engagement, and Feminist Pedagogy in the Photographic Work of Pamela Harris

Liisa Graham

Master of Arts, 2015

Film and Photography Preservation and Collections Management (FPPCM)

Ryerson University, Toronto

\section{ABSTRACT}

This thesis project analyzes the Pamela Harris Spence Bay Collection, held at the Art Gallery of Ontario (AGO). It is comprised of photographic work produced by Harris while in the Inuit community of Spence Bay, in 1972 and 1973, as well as photographs and documents pertaining to the community darkroom Harris initiated. Harris's photographs capture an Inuit community in transition, encompassing both Northern and Southern ways of being, and analyzed within the historical context of photographic representation of Indigenous communities. The community darkroom is examined through a feminist pedagogical framework, and illustrates how community members utilized photography as a tool of empowerment. This project is analyzed within the political and social contexts of the late 1960s and early 1970s, and explores the themes of community engagement, the politics of representation, and empowerment, and argues that Harris's social consciousness contributed to a shift in Indigenous visual discourse. 


\section{ACKNOWLEDGEMENTS}

I would like to thank my first reader, Sophie Hackett, Associate Curator of Photography at the Art Gallery of Ontario, for her enthusiasm, encouragement, advice, and guidance during the development of this research project. I would also like to thank Amy Furness and Marilyn Nazar of the AGO's E.P. Taylor Research Library and Archives, for their assistance and insight in this project.

Thank you also to my second reader Blake Fitzpatrick, for your suggestions and insight.

I wish to thank the many professors, instructors, and individuals at Ryerson University's School of Image Arts: Don Snyder, David Harris, Bob Burley, Phil Bergerson, Marta Braun, Peter Higdon, who, during my undergraduate and graduate studies, all inspired my continued love of the photographic arts.

And of course, Pamela Harris. Thank you for giving me your time, and sharing your memories and wonderful stories with me. You were an incredible source of information, I could not have written this paper without your insights. I thank you immensely.

To my loved ones, who never stop believing and supporting me in all my endeavours, thank you, I love you.

Liisa Graham

August, 2015 


\section{CONTENTS}

Author's Declaration...................................................................................... ii

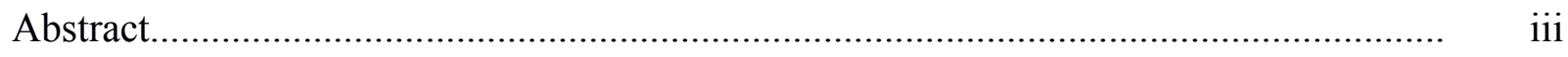

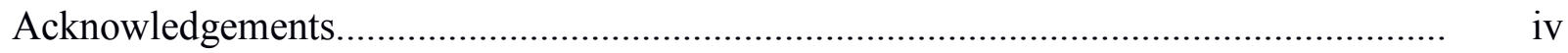

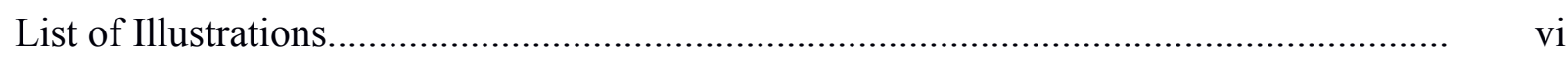

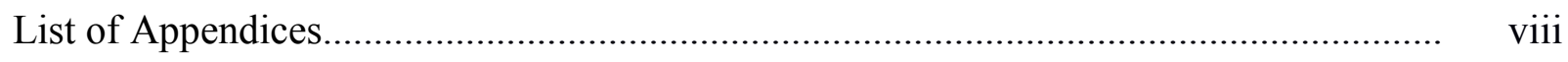

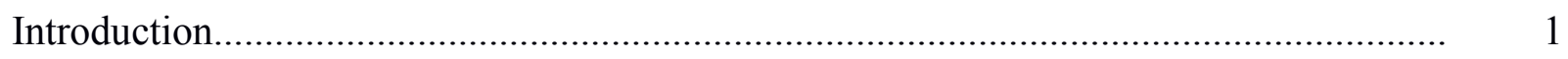

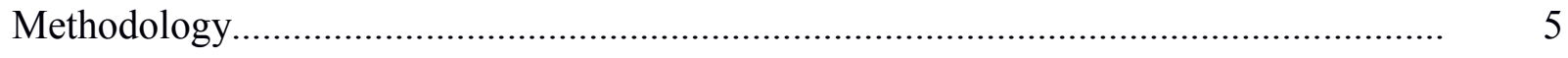

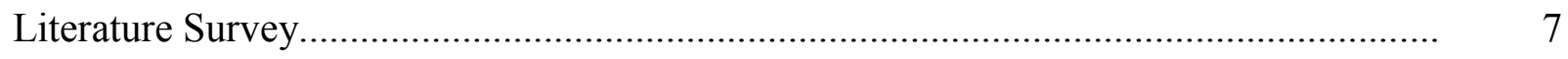

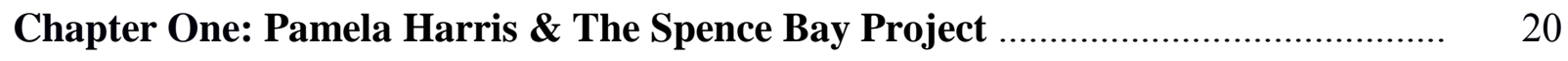

Chapter Two: The Photographs - Particulars of Place \& Approach....................... 28

i. Why Spence Bay......................................................................... 28

ii. Community Engagement \& Inuit Representation............................. 31

Chapter Three: The Darkroom Project.................................................................

i. "Cooking up Pictures:" 48

ii. The Photographer \& The Photographed:

Voice, Power, \& Representation...................................................... 55

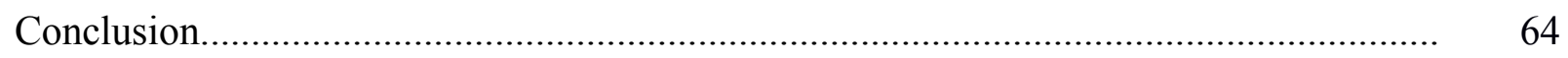

Appendix A - Pamela Harris Interview Questions \#1 \#........................................... 67

Appendix B - Pamela Harris Interview Questions \#2............................................... 69

Appendix C - Excerpt from “A Conversation” in Another Way of Being ........................ 70

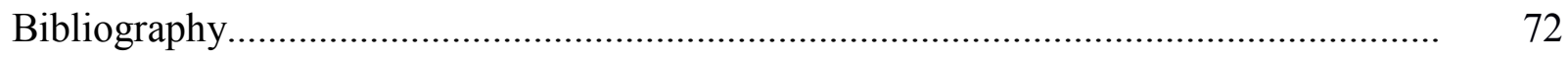




\section{LIST OF ILLUSTRATIONS}

All illustrations are reproductions of Pamela Harris gelatin silver prints from the collection of the Art Gallery of Ontario, Toronto, ON, unless otherwise noted.

Fig. 1 Unknown, Pamela Harris at the Arctic Women's Workshop in Toronto, 1974, in Arctic Women's Workshop [June 1974]: 43.

Fig. 2 Location of Spence Bay in Relation to Toronto. Map by Chahé Sabag, Another Way of Being, 59. Addition of red circles made by author.

Fig. 3 Another Way of Being, book cover. Photograph: Tulurialik and Neeveeakchuk Waiting to Sell Carvings, 1972.

Fig. 4 Joannie Saituk Playing Accordian, 1972/73. 22

Fig. $5 \quad$ Children (in Woody Woodpecker Jackets), 1972.

Fig. 6 Mary Edetoak (Old Mary) on her Bed, with Dolls, 1972.

Fig. 7 Gemma Unalerk and Mailbag Tent, Netsilik River, 1973.

Fig. $8 \quad$ Family Sleeping (Cambridge Bay), 1973/73. 26

Fig. $9 \quad$ Jude Iqalliyuq, 1972/73. 27

Fig. 10 Pauloosee Jayko (The Day the Boat Came In), 1972/73. 27

Fig. 11 Spence Bay from the Air, 1972/73. 28

Fig. 12 Judy McGrath with the Spence Bay Natural Dye Recipe and Sample Book, in Arctic Women's Workshop [June 1974]: 25.

Fig. 13 Nilaulaq Fingerweaving on the Way to Netsilik Camp, 1973.

Fig. 14 Mary Neeveakcheak in her Room (Posters), 1973.

Fig. 15 Pauloosee Jayko (The Day the Boat Came), 1972/73. 37

Fig. $16 \quad$ Storage Tanks, $1972 . \quad 37$

Fig. 17 Karoo Ashevak Carving, 1972/73. 40 
Fig. 18 Napachee Kallak and Joanie Saittuq Stepdancing, 1972/73.

Fig. 19 Nilauloq and Willie in Darkroom, 1973.

Fig. 20 Nilauloq and Willie in Darkroom, 1973.

Fig. 21 Selena Tucktoo in Darkroom, 1973.

Fig. 22 Loui and Friend in Darkroom, 1973.

Fig. 23 Darkroom Project instructional materials, courtesy of the Pamela Harris Collection at the AGO's E.P. Taylor Research Library and Archives.

Fig. 24 Theresa Quaqjuaq, Untitled, 1973/74.

Fig. 25 Unknown Photographer, Untitled, 1973/74.

Fig. 26 Selena Tucktoo, Untitled, 1973/74.

Fig. 27 Teresa Totalik, Untitled, 1973/74.

Fig. 28 The Spence Bay Photo Show at the Arctic Women's

Workshop, in Arctic Women's Workshop [June 1974]: 79.

Fig. 29 The Spence Bay Photo Show at the Arctic Women's

Workshop, in Arctic Women's Workshop [June 1974]: 79. 


\section{LIST OF APPENDICES}

Appendix A Pamela Harris Interview Questions \#1 - March 20, 2015, Toronto, ON. 67

Appendix B Pamela Harris Interview Questions \#2 - May 14, 2015, Art Gallery of Ontario, Toronto, ON.

Appendix C Excerpt from “A Conversation” in Another Way of Being, 11-12. 


\section{INTRODUCTION}

In 1972 and 1973, Pamela Harris (fig. 1), an American-born, self-taught photographer, travelled to the Inuit community of Spence Bay, ${ }^{1}$ then located in the Northwest Territories. At the time, Harris was in her early 30s and based in Toronto. On her first trip in 1972, she spent several weeks photographing the people and the landscape of this Arctic community. She returned in 1973 and continued her documentary work for three months. During this trip she also built a community darkroom in the local women's craft shop, and taught anyone who wanted to learn how to produce their own photographs.

Spence Bay is located just under 3000 kilometres from Toronto (fig. 2), on the Boothia Peninsula, in Nunavut. The Hudson's Bay Company established it as a trading post in the 1950s, and soon after, other institutions began to move in as well: a school, the Royal Canadian Mounted Police (RCMP), and a nursing station, to name a few. For Harris, it took approximately three days to travel there, on three different planes. She photographed Spence Bay at a time of significant transition, and wrote:

It is certainly understandable that people would make this move, even though many regretted leaving the life on the land ... To live through the Arctic winter in a warm, lighted house, to buy food at a store when no fresh meat can be killed, to have the help of a nurse when a child is sick: these things are good.... But these new advantages cannot be chosen in isolation, for they draw with them an entirely new way of life, directed by the South and dependent upon it. In the myriad of experiences are many things, whether positive or negative, that people enjoy. It is this very enjoyment of the new that makes it difficult for those experiencing the changes to evaluate what is being lost; and it also makes it difficult for an outsider to make judgments about what is happening - everything is double-edged.

\footnotetext{
${ }^{1}$ Spence Bay was renamed Taloyoak in 1992. However, for clarity, and because Harris incorporated Spence Bay into the title of the project, I will refer to it as Spence Bay throughout this paper.

${ }^{2}$ Pamela Harris, Another Way of Being: Photographs of Spence Bay N.W.T. (Toronto: Impressions, 1976), 4.
} 
As a documentary photographer, Harris made a variety of photographs while in Spence Bay, the majority of them portraits. They capture moments and activities that depict old and new ways of living, both on the land and in the town, and what she refers to as the tension between Northern and Southern ways of being. She was conscious of being a guest within the community, a visitor whose role was to photographically document what she saw. Harris's outsider status led to her careful examination of both her approach to her own photographic work, and to the community darkroom project.

Harris came of age in the 1960 s, an era that saw the height of second-wave feminism. ${ }^{3} \mathrm{~A}$ time rich with social justice, anti-war movements, and a mentality that encouraged self-initiated endeavours. This was also a time when pedagogical discussions focused on popular education, a form of teaching that promoted an equal exchange between teacher and student, and attempted to reduce the hierarchical structures of conventional academic institutions. Harris had connected with the people at This Magazine is About Schools, a "radical magazine about schools"4 produced in Toronto from 1966-1973. ${ }^{5}$ Their editor states, "It is a stamp of our age to believe that 'nothing can be done' about the things we don't like. One of the results of this is that we rarely even hear about experiments which disprove this view.... This Magazine intends to report such experiments, and to suggest what can be learned from them." ${ }^{6}$ Coming of age during this

\footnotetext{
3 "The term second-wave feminism refers mostly to the radical feminism of the women's liberation movement of the late 1960s and early 1970s.... it grew out of leftist movements in postwar Western societies, among them the student protests, the anti-Vietnam War movement, the lesbian and gay movements, and, in the United States, the civil rights and Black power movements. These movements criticized 'capitalism' and 'imperialism' and focused on the notion and interests of 'oppressed' groups: the working classes, Blacks, and in principle, also women and homosexuals." Charlotte Kroløkke, "Three Waves of Feminism: From Suffragettes to Grrls," in Gender Communication Theories \& Analyses: From Silence to Performance (Thousand Oaks, CA: Sage Publications, 2006), 7, 8-9.

${ }^{4}$ Robert Davis, "Editorial," This Magazine is About Schools 1, no. 1 (April 1966): 1.

${ }^{5}$ Harris photographed for several articles featured in This Magazine About Schools, including "Getting to Rochdale" vol. 2, no. 1 (Winter 1968): 72-96, and "Will it Live in a Milk-Carton? City Kids Discover Nature" vol. 2, no. 2 (Spring 1968): 31-38. The publication changed its name to This Magazine in 1973.

${ }^{6}$ Davis, "Editorial," 1-2.
} 


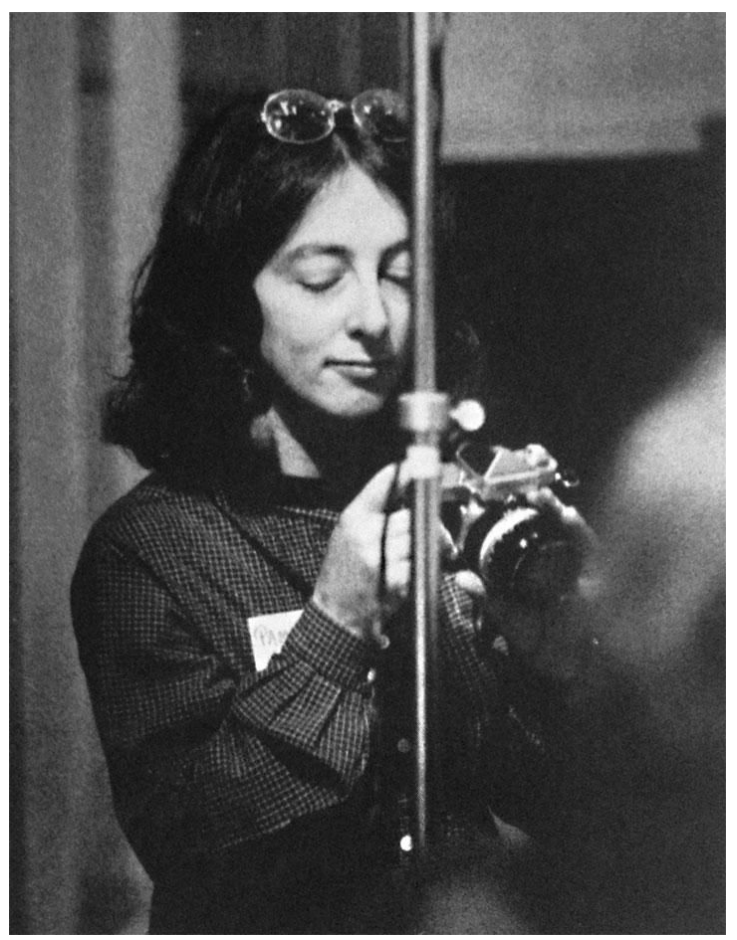

Figure 1. Unknown Photographer. Pamela Harris at the Arctic Women's Workshop in Toronto, 1974.

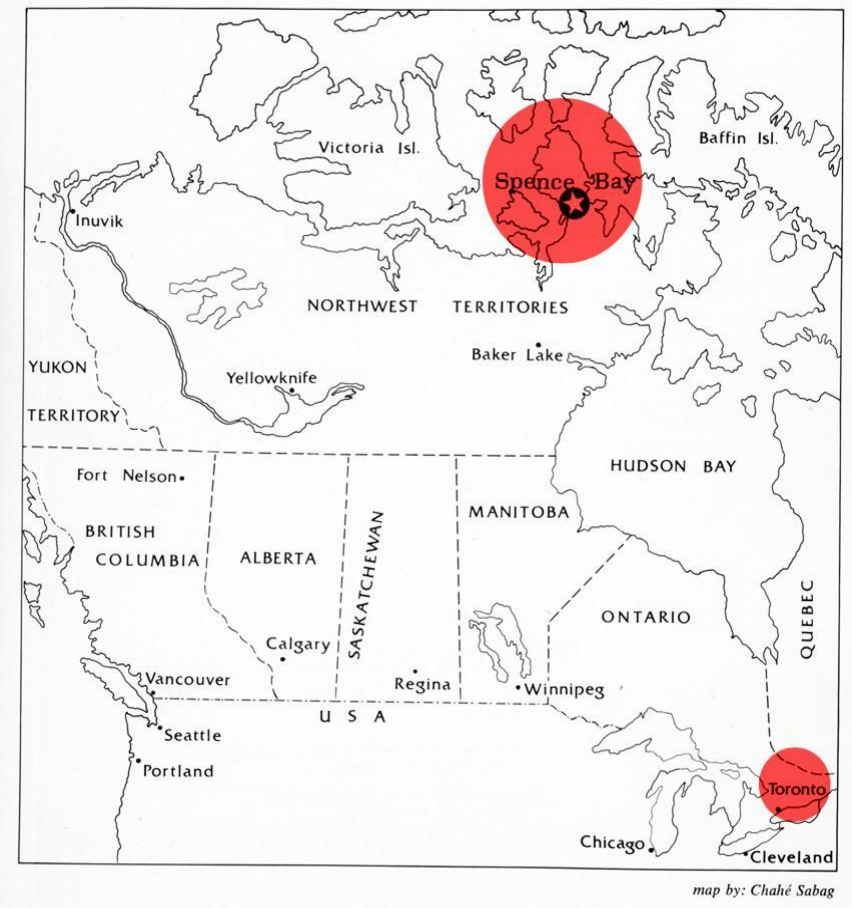

Figure 2. Location of Spence Bay in Relation to Toronto. 
era had a profound effect on Harris. It influenced what photographic projects she undertook, and shaped her approach in how they were carried out. In Spence Bay she witnessed a community undergoing a significant cultural shift; a community often overlooked or misrepresented; and, to her, a community worth documenting.

The practice of traveling and photographing in the Canadian North is nothing new or unique. However, the majority of historical photographs of Indigenous ${ }^{7}$ people have been made by outsiders, for outsiders. ${ }^{8}$ Hence the importance of examining Harris's work within the context of the political and social climate of the late 1960s and early 1970s, and situating her in this transformative era when she produced the Spence Bay project, not only for outsiders, but for insiders as well. In so doing, I will illustrate how her work compares to the work of others who travelled to and photographed the North, and ultimately what sets her apart from her predecessors. Harris was directly influenced by ideas of equality, exploitation, and power over one's own representation. She sought to engage and empower the community she worked with, by including them in both the production and process of creating photographs. This mutual engagement is what distinguishes her from the Northern image makers that came before her, and constitutes a significant contribution to Indigenous visual discourse.

\footnotetext{
${ }^{7}$ The majority of the scholarly research consulted for this thesis uses the term Aboriginal. In light of more recent conversations surrounding appropriate terminology, I have opted to use the term Indigenous instead, as Aboriginal is considered by some to be problematic: "It's an English word, and it's not what they call themselves. Most people assume the word aboriginal means 'the first inhabitants' or 'from the beginning.' But the root meaning of the word 'ab' is a Latin prefix that means 'away from' or 'not.' And so aboriginal can mean 'not original.'” Don Marks, "What's in a Name: Indian, Native, Aboriginal or Indigenous?” CBC News, October 2, 2014, $\mathrm{http} / /$ www.cbc.ca/news/canada/manitoba/what-s-in-a-name-indian-native-aboriginal-or-indigenous-1.2784518. ${ }^{8}$ Dan Savard, Images from the Likeness House (Victoria B.C.: Royal BC Museum, 2010), 143.
} 


\section{METHODOLOGY}

Determining the methodology for my research began with the realization that aside from several magazine and newspaper articles, and Harris's own written documents, including Another Way of Being: Photographs of Spence Bay N.W.T., there was not a lot of written material on Pamela Harris's Spence Bay project. Fortunately, Harris lives in Toronto, and I was able to meet with her on several occasions, to discuss her work. I conducted two recorded interviews with her; the first took place at her home on March 20th, 2015, and the second took place at the Art Gallery of Ontario (AGO), with her photographic prints, on May 14th, 2015. Interviewing her offered an invaluable amount of information and insight for this project.

The main bodies of work I studied were Pamela Harris's Spence Bay photographs in the AGO's collection, and the archival material held in the AGO's E.P. Taylor Research Library and Archives. Much of my time was spent closely observing Harris's photographic work and reading through archival documents, including correspondence. Harris made two separate trips to Spence Bay, each with its own focus. The first was to primarily create photographic work, and the second to create a community darkroom. Thus it became clear that the logical approach was to divide the research and the resulting thesis paper into two main sections: The Photographs, and The Darkroom. I also researched the broader historical context of photographic representations of Indigenous subjects in Canada, in order to garner an understanding of past practices, and to observe what aspects made Harris's work different. These differences are analyzed within the political and social climate of the late 1960s and early 1970s, the era when Harris came of age. It is clear that her socially conscious background shaped her approach, and discussing her work through this lens provides great insight into how and why these differences occurred. 
The photography section is discussed in terms of community engagement and participation. I discuss how Harris's social concerns related to creating photographic work alters the representation of Indigenous people, especially when compared to the historical practices of photographing the North. The darkroom project is analyzed through a feminist pedagogical framework, and discussed as a means of community empowerment which resulted in a significant shift in Indigenous photographic perspective and representation. 


\section{LITERATURE SURVEY}

This literature survey examines several topics relevant to Harris's project in Spence Bay. These texts are divided into four sections, beginning with books and articles that discuss the history of Indigenous photography by non-Indigenous photographers, followed by writings that analyze photographic representations of Indigenous subjects. These texts place Harris's Spence Bay project in a historical context—how it was conducted, why, and by whom. They illustrate the visual conventions established by her predecessors, which offers a basis for comparison with Harris's work: how it differed, why, and the resulting social impact. These texts also provide the context necessary to examine the themes of power, empowerment, representation, and "otherness" in photographic representations of Indigenous subjects. Following that, writings on feminist pedagogy offer an analytic framework to approach the darkroom project. Again, themes of "otherness" and empowerment are explored, as well as the ways in which Harris's feminist perspective shaped her approach to teaching in a community with linguistic and cultural barriers. Finally, material produced directly by or about Harris and the Spence Bay project serves to compliment her body of work by illustrating how it was discussed and disseminated in mass media.

\section{a. History of Indigenous Photography Produced by Non-Indigenous People}

The discussion of these texts illustrates past historical practices of Indigenous photography by non-Indigenous people, and compares them to Harris’s work. ${ }^{9}$ By doing so, one

\footnotetext{
${ }^{9}$ Amongst the many non-Indigenous photographers of the Canadian Arctic, it should also be noted that Inuit artist Peter Pitseolak began creating photographic work in the early 1940s. He is considered the first Indigenous documentary photographer in the Canadian Arctic. I am not discussing him in this thesis paper because the focus is
} 
gains a better understanding of how her approach differs, and the significance of these differences. In this section, work produced by the following photographers will offer a basis for comparison: Geraldine Moodie (1854-1945), Robert Flaherty (1884-1951), and Richard Harrington (1911-2005). Comparisons will include the approach or style employed by the photographer, possible perspectives and/or attitudes that influenced those decisions, and the social contexts of the time period.

Donny White discusses Geraldine Moodie in the chapter, "In Search of Geraldine Moodie: A Project in Progress." ${ }^{10}$ Moodie was a female studio photographer who photographed in the Canadian Arctic in the early 1900s. She joined her husband, J.D. Moodie, aboard the government expedition vessel Neptune, where "she set about familiarizing herself with her new surroundings and establishing a rapport with the Inuit whalers and their families, who would become the primary focus of her photography...."11 In Framing Identity: Social Practices of Photography in Canada, 1880-1920, ${ }^{12}$ Susan Close explains that Moodie predominantly photographed portraits in neutral studio environments, and argues that they were arranged to "create the consciously and carefully constructed images of romanticized motherhood required by the colonial imagination..." ${ }^{13}$ Subjects are posed, in traditional clothing, and often look at the camera. On occasion they face another person in the frame, such as a child. Moodie was drawn to create photographic work of the Inuit, in part, because she recognized its value as a

on the work produced by non-Indigenous photographers, a status that applies to Harris. Dorothy Harley Eber, "Peter Pitseolak and the Photographic Template," in Imaging the Arctic, eds. J.C.H. King and Henrietta Lidchi (Seattle: University of Washington Press, 1998), 53.

${ }^{10}$ Donny White, "In Search of Geraldine Moodie: A Project in Progress," in Imaging the Arctic, edited by J.C.H. King and Henrietta Lidchi, 88-97 (Seattle: University of Washington Press, 1998).

${ }^{11}$ Ibid., 91-92.

${ }^{12}$ Susan Close, Framing Identity: Social Practices of Photography in Canada, 1880-1920 (Winnipeg: Arbeiter Ring, 2007).

${ }^{13}$ Ibid., 57. 
commodity that, as Close argues, would "raise her profile and advance her career as a professional photographer." Harris, on the other hand, never treated her subjects as specimens to be profited from. Close also writes about Moodie in the context of being a woman, and inquires if Moodie's gender alters her production of photographic work. Close asks: "Does her perspective as a woman, another marginalized other, make her representation of her Inuk subjects different? Does she produce a more sympathetic rendering of her subject?" ${ }^{15}$ Close discusses theories developed by others and suggests that photographs made by women display "a recognizably greater degree of empathy toward their subjects.... portraits made by women tend to be 'less grim' and more 'eye-to-eye' than those made by men." ${ }^{16}$ Eye contact, the subject's gaze, and depicting an expressive relationship between family members, ${ }^{17}$-also present in Harris's work — will serve as a basis for comparison. White also describes the significance of Moodie's gender, which provides an alternative perspective in creating photographic work, and how, "Judging from her portraiture work, the Inuit were at ease and comfortable with Geraldine, especially the women and children, who appear in many of her images." ${ }^{18}$ Though there are some paralells, Harris exclusively photographed people in natural environments, thus producing work in an entirely different context than Moodie. ${ }^{19}$ The lack of natural environments in Moodie's photographs lessens or omits the site-specific context of her subjects. In Harris's work, however, the inclusion of the natural environment aids the viewer in receiving particular character attributes, and highlights the importance of location and environment.

\footnotetext{
${ }^{14}$ Ibid., 51, 104.

15 Ibid., 56-57.

${ }^{16}$ Ibid., 51.

${ }^{17}$ Ibid., 54, 58, 59.

${ }^{18}$ White, "In Search of Geraldine Moodie," 92, 93.

${ }^{19}$ That said, the technical limitations of photography in the early 1900s must be acknowledged, as that is a factor in the type of photographic images one was able to produce, especially in the Canadian Arctic.
} 
Robert Flaherty, primarily a filmmaker known for his film Nanook of the North (1922), also created still photographs of Inuit people. The exhibition catalogue, Robert Flaherty, Photographer/ Filmmaker: The Inuit, 1910-1922: An Exhibition, states that Flaherty took nearly a thousand photographs during several expeditions between 1910 and $1916^{20}$ In the introduction, curator Jo-Anne Birnie Danzker discusses his work in relation to the Inuit people he lived and travelled with, highlighting the relationships that developed between them. The book goes on to discuss these relationships, and how this affected his photographic work: "As Flaherty's intimacy with the Inuit increased, his camera began to locate and isolate the personality of his companions rather than their exotic lifestyle and modes of dress." ${ }^{21}$ The majority of Flaherty's portraits are close-ups, which tend to fall into two categories: "Studio-Type," where subjects are posed in conventional 19th century style portraits, with little or no eye contact; and "Confrontation," in which "the viewer is literally confronted, through direct eye contact, by the subject." ${ }^{22}$ His images evoke a sense of the subject as historical figure, whose existence has a place in the past, though perhaps not in the future. They are mesmerizing-emotive yet stoic, mysterious and distant. Yet, the directional posing of his subjects produces images that are of Flaherty's vision, drawing attention to the creator. Harris, on the other hand, who did not direct her subjects in the same fashion, created photographic work that defers more authority to the subject, and not on her as the photographer. Harris also employs direct eye contact between subject and viewer, a significant factor in distinguishing the similarities and differences amongst those who photographed Indigenous communities.

\footnotetext{
${ }^{20}$ Robert Flaherty, Robert Flaherty, Photographer/Filmmaker: The Inuit, 1910-1922: An Exhibition (Vancouver: The Vancouver Art Gallery, 1979), 5.

${ }^{21}$ Ibid., 25.

${ }^{22}$ Ibid., 26
} 
Richard Harrington, a photographer and writer, photographed Inuit communities extensively between 1947 and 1953. He lived and travelled with the Inuit, producing thousands of photographs, ${ }^{23}$ some of which can be seen in his book, The Inuit: Life As It Was. ${ }^{24}$ This book is predominantly made up of his photographs and accompanying text, all from Harrington's perspective. The photographs are his interpretation of the Inuit way of life, encompassing the themes of survival, fortitude, and happiness. The book Richard Harrington: Canadian Photographer, ${ }^{25}$ includes a selection of his Inuit photographs in the "Canada" section. Again, the images are accompanied by short captions, and describe the people and the situation of the photograph. In both books the captions describe the Inuit in general terms, and, aside from a few instances, people are not referred to by name, but simply by, "the hunter," "this Inuit mother," "this young Inuk," etc. Harris's use of text, on the other hand, incorporates direct quotes from individuals in the community, and always refers to them by name. Harrington, like Harris, photographs people in their natural environments, and focuses on a variety of activities and subject matter pertaining to hunting, food, clothing, children, traditions, etc. Also, both photographers were aware of the changing Inuit culture, and express concern for, or empathy with, the Indigenous community's future. The subtitle of Harrington's book, Life As It Was, suggests that the Inuit were now a culture of the past, and without a future in contemporary society. Harrington's attitude contrasts fundamentally with Harris's. She utilized the social changes she witnessed as an opportunity to empower the Inuit, instead of mourning their supposed cultural destruction. There is no sense of Harris idealizing or romanticizing her subject matter as objects to be preserved through photographic images. Further, the title, Another Way of

\footnotetext{
${ }^{23}$ Richard Harrington, The Inuit: Life As It Was (Edmonton: Hurtig Publishers, 1981), 12.

24 Ibid.

${ }^{25}$ Richard Harrington, Richard Harrington, Canadian Photographer (Edmonds, WA: Alaska Northwest, 1998).
} 
Being indicates that she did not view them as a vanishing people, but rather a culture in transition-one whose future entails a new mode of existence.

\section{b. Writing, Discussing and Analyzing Photographic Representations of Indigenous Subjects}

In his book, Northern Exposures: Photographing and Filming the Canadian North, $1920-45,{ }^{26}$ educator and historian Peter Geller discusses the nature of Southern photographic image-making within a Northern Canadian context. He investigates which individuals and organizations were producing these photographs (namely the Canadian government, the Anglican Church, and the Hudson's Bay Company), ${ }^{27}$ places them in a historical context, and analyzes their role in shaping Canadian national identity. Geller writes, "Northerners and the land they inhabited were caught in the observer's gaze and, in the process, transformed."28 This “transformation" refers to the photographer's mandate, in which what they desire to capture and accomplish with photography transforms their subject into the very thing that will accomplish these goals. He also points to the omission of names, which are "replaced by the generalized title 'Native Type' and standing in stark contrast to the portraits of named whites." ${ }^{29}$ These topics highlight the power dynamic that can exist between the photographer and the photographed, an issue discussed throughout this paper, in relation to Harris's work, and specifically how her approach acted against these past practices.

Carol Payne is the author and editor of several works that discuss the nature of Indigenous photography in Canada. In her essay, “Through a Canadian Lens: Discourses on

\footnotetext{
${ }^{26}$ Peter Geller, Northern Exposures: Photographing and Filming the Canadian North, 1920-45 (Vancouver: University of British Columbia Press, 2004).

${ }^{27}$ Ibid., 6.

${ }^{28}$ Ibid., 11.

${ }^{29}$ Ibid., 35 .
} 
Nationalism and Aboriginal Representation in Governmental Photographs," Payne explains that photography is a "social practice" that is "historically inscribed [by] the biases and concerns of the culture and times in which it was developed and viewed." ${ }^{30}$ Both this essay and the interview she conducted with Iroquoian artist and curator Jeffrey Thomas, entitled, "Aboriginal Interventions into the Photographic Archives: A Dialogue Between Carol Payne and Jeffrey Thomas," discuss how photography was used to construct images of Indigenous people to further colonialist attitudes, and how disregarding names renders Indigenous peoples as the nation's "other." Thomas describes his encounter with Indigenous photographs as one predicated on frustration: "When I was a young boy and would come across photographs of First Nations people, I had the sense that they had something to say to me. I remember feeling frustrated by this because the images usually didn't offer any personal information about the people I was looking at. And, I wondered if anyone really knew who they were." ${ }^{32}$ Harris, on the other hand, was adamant about recording people's names and stories, and included them alongside her photographic work. This illustrates how her approach was significantly different from her predecessors and, as a result, included what had been predominantly missing in Indigenous visual history.

In "Returning Fire, Pointing the Canon: Aboriginal Photography as Resistance," Sherry Farrell Racette describes how the camera becomes a tool of resistance and de-colonization for Indigenous photographers within the historical context of colonization and feminist theory. ${ }^{33}$ She

\footnotetext{
${ }^{30}$ Payne, "Through a Canadian Lens: Discourses on Nationalism and Aboriginal Representation in Governmental Photographs," in Canadian Cultural Poesis: Essays on Canadian Culture, edited by Garry Sherbert, Annie Gérin, and Sheila Petty (Waterloo, ON: Wilfred Laurier University Press, 2006), 423.

${ }^{31}$ Ibid., 109.

${ }^{32}$ Ibid., 119.

33 Sherry Farrell Racette, "Returning Fire, Pointing the Canon: Aboriginal Photography as Resistance," in The Cultural Work of Photography in Canada, edited by Carol Payne and Andrea Kunard (Montreal: McGill-Queen's
} 
discusses several expedition photographers, many employed by the Hudson's Bay Company, and then compares them with the creative projects produced by Indigenous people who have utilized the camera as a tool for reclaiming their representation, and articulating their creative vision. She writes, "Their respective practices both celebrated and served as witness. Together they left a legacy of thousands of photographs that had recorded their communities with a lens that occupied a space that was neither ethnographic nor exclusively familial. It was shared, collective space in which the photographer documented 'ourselves for ourselves' and extended the collective gaze toward the land." 34 These ideas resonate with Harris's community darkroom project, insofar as the participants documented their own lives, for themselves, and the empowerment associated with this practice.

In "Lessons with Leah: Rereading the Photographic Archive from the North," Carol Payne discusses how images of the Canadian North were constructed by those in the South (or non- Indigenous), often portraying them namelessly, and thus positioning them "as anonymous cultural 'types' rather than historic individuals." ${ }^{35}$ She analyzes the work of Richard Harrington, who often did not record people's names, to show how visual repatriation initiatives, such as "Project Naming," 36 have allowed for the identification of previously unidentified Indigenous subjects in photographs. ${ }^{37}$ Again, Harris's commitment to recording people's names indicates her

University Press, 2011), 70.

${ }^{34}$ Ibid., 79.

${ }^{35}$ Carol Payne, The Official Picture: The National Film Board of Canada's Still Photography Division and The Image of Canada, 1941-1971 (Montreal: McGill-Queen's University Press, 2013), 181.

36 "Project Naming seeks to identify some of the thousands of Inuit depicted in images from the LAC's photographic collections in Ottawa.... Elders responded to images viewed on the [computer] screen.... each researcher asked the following questions about the images: 'Do you know who is in the picture? Do you know where it was taken? Can you describe what is happening in the picture? What was life like for Inuit back then?' The researcher... asked the elder to confirm the spelling of the photographic subjects' names in English, Inuktitut, and Innuinaqtun. It is important to note that Project Naming does not include full oral histories." Ibid., 181, 183.

${ }^{37}$ Ibid., 183. 
awareness of the importance of doing so, in order for her subjects to maintain their individual identities.

\section{c. Feminist Pedagogy}

The first feminist text that Harris read was Betty Friedan's The Feminine Mystique, ${ }^{38}$ and from there she went on to explore the writings of Germaine Greer, Kate Millett, and Shulamith Firestone, among others. ${ }^{39}$ As a feminist, the politics embedded in feminist literature influenced Harris's educational practices. She developed a non-hierarchical model of teaching and learning that challenged oppressive structures while examining the role of power and, consequently, empowerment. Therefore, it is only appropriate to analyze her approach to the darkroom project through the field that is now known as feminist pedagogy.

In her article, “What is Feminist Pedagogy?” Carolyn M. Shrewsbury offers a basis for understanding the ideas and practices of feminist pedagogy. She describes it as:

a vision of the classroom as a liberatory environment in which we, teacher-student and student-teacher, act as subjects, not objects. Feminist pedagogy is engaged teaching/ learning - engaged with self in a continuing reflective process; engaged actively with the material being studied; engaged with others in a struggle to get beyond our sexism and racism and classism and homophobia and other destructive hatreds and to work together to enhance our knowledge; engaged with the community, with traditional organizations, and with movements for social change.

\footnotetext{
38 “Betty Friedan's 1963 book The Feminine Mystique exploded the myth of the happy housewife in the affluent, white, American suburbs; 'the problem that has no name', she wrote, 'burst like a boil through the image of the happy American Mystique'.... But Friedan's book was a well-researched, sharply written, even passionate indictment of the fact that even affluent middle-class women lead restricted lives, and too often lapse into a depressed acceptance of that restriction. She insisted that each woman must at least ask what she truly wants. Then she may indeed realize that 'neither her husband nor her children nor the things in her house, nor sex, nor being like all the other women, can give her a self '. Friedan's own background had been in radical politics, and her earlier writings, particularly, display a keen awareness of social inequalities." Margaret Walters, "Second-Wave Feminism: The Late 20th Century," in Feminism: A Very Short Introduction (Oxford: Oxford University Press, 2005$), 102$.

${ }^{39}$ Pamela Harris, e-mail message to author, July 29, 2015.

${ }^{40}$ Carolyn M. Shrewsbury, "What is Feminist Pedagogy?” Women's Studies Quarterly 25, no. 1/2 (Summer 1997): 166.
} 
This philosophy is reflected in Harris's focus on engaging with the community of Spence Bay - in terms of an engagement with their stories through her own photographic work, and their engagement with photography in order to represent their lived experiences.

Feminist Pedagogy: Looking Back To Look Forward, edited by Robbin D. Crabtree, David Alan Sapp, and Adela C. Licona, poses these questions: "What do we teach and why? How do we teach and why? How does what and how we teach impact our students and our communities?" Pamela Harris answers these questions in documented writings pertaining to the darkroom project in Spence Bay. She discusses her motivations for the project, her goals, her methodological approach, and the implications - all of which can be linked to feminist beliefs. These aspects will be discussed in greater detail in "The Darkroom" chapter of this paper. Crabtree, et al, suggest that, "Feminist pedagogy emphasizes the epistemological validity of personal experience, often connected to notions of voice and authority.... [It] questions the ways traditional knowledge production and received knowledge serve particular interests and social configurations of power through the systematic exclusion or oppression of particular classes of people." $" 42$

In "Revaluing Female Voices," ${ }^{43}$ Carrie F. Paechter discusses the nature of power relations in a pedagogical context, and questions whose voices are heard in various circumstances. This is applicable to Harris's work because, traditionally, photographs of Indigenous people have been constructed from the perspective of the non-Indigenous, who have often fulfilled their own goals via suppressing the voice of the subject being depicted. In order to

\footnotetext{
${ }^{41}$ Robbin D. Crabtree, David Alan Sapp, and Adela C. Licona, eds., Feminist Pedagogy: Looking Back To Look Forward (Baltimore: John Hopkins University Press, 2009), 3.

${ }^{42}$ Crabtree et al., Feminist Pedagogy, 4.

${ }^{43}$ Carrie F. Paechter, Educating the Other: Gender, Power, and Schooling (London: Falmer Press, 1998), 64-79.
} 
shift the power dynamic, space must be given to those who have been historically silenced, which was the goal of the darkroom project. ${ }^{44}$

The themes of voice, power, and representation, all apparent in Harris's thoughts and writings on the darkroom project, echo the ideas present in feminist pedagogical theory. ${ }^{45}$ The above texts offer a framework to analyze these aspects of the darkroom project, and their implications for Indigenous visual culture.

\section{d. Writings Pertaining to Pamela Harris and Her Work}

\section{i. Books by Pamela Harris}

Pamela Harris produced Another Way of Being: Photographs of Spence Bay N.W.T. as a result of her time and work in the arctic community. The book offers a selection of Harris's photographs, alongside her writing that incorporates stories and perspectives from Inuit people in the community, and interview excerpts. She acknowledges, as a documentary photographer, that she did not aim to speak for anyone else, and that, "The real story of the North must be told by the Inuit themselves." ${ }^{46}$ The book illustrates the diversity of her subjects. Through this representation of diversity, Harris helps to dispel stereotypical images of Indigenous people, an act that exemplifies and supports her feminist philosophy. Similarly, Harris's later book, Faces of Feminism: Portraits of Women Across Canada,${ }^{47}$ combines text and images in order to present the voice of the photographed individual alongside their visual image. Lisa Steele writes in the

\footnotetext{
${ }^{44}$ Ibid., 67.

${ }^{45}$ I am using the term 'voice' to refer to visual representations of perspective, and not in the literal sense, as photographs do not actually speak.

${ }^{46}$ Harris, Another Way of Being, 5.

${ }^{47}$ Pamela Harris, Faces of Feminism: Portraits of Women Across Canada (Toronto: Second Story Press, 1992).
} 
preface: "Harris has a way of making portraits that allows content to pour into the isolated frame. By heightening the narrative qualities of the photographs, she increases the viewer's desire to look inside, to get to know these women, to engage." 48 The portraits are captured in various personal environments and depict the diversity that exists within the women's movement, just as the variety of Spence Bay photographs depict the diversity within their community. Both projects were a result of collaborative work between Harris and the community photographed, and, as Harris writes: "all of them have a presence in the project, for it was built with their aid." 49 These two texts compliment each other in methodology and execution, and provide a broader understanding of Harris not only as a photographer, but as a feminist.

\section{ii. Newspaper and Magazine Articles Pertaining to Pamela Harris's Spence Bay Project}

Pamela Harris's photographs appeared in several publications shortly after the Spence Bay project took place, between 1974 and 1978. Some are pieces written by others and include photographs by Harris, and some are photoessays compiled by Harris herself. The photoessays include excerpts from Another Way of Being, and alternative, original selections of photographs and accompanying text. Examining this material helps establish an understanding of how and why her photographs were reproduced and disseminated, in the context of the era in which they were made.

In the article, "Photography Helps Inuit Control Changing Culture," published in the Toronto Star, ${ }^{50}$ journalist Gary Michael Dault reviews the Spence Bay project, and Harris’s

\footnotetext{
${ }^{48}$ Ibid., 9.

${ }^{49}$ Ibid., 171.

${ }^{50}$ Gary Michael Dault, “Photography Helps Inuit Control Changing Culture,” Toronto Star, July 2, 1976.
} 
exhibition at the David Mirvish Gallery in Toronto. He describes the photographic work with praise: "Harris is both a consummately skillful technician and a superbly controlled intuitive artist, [and] demonstrates [a] splendid command of both the precise moment that most accurately reveals the nature of personality, and the esthetic moment that offers the perfectly composed photograph." 51 In the piece, "Photography at Spence Bay, N.W.T.," featured in Focus Magazine, ${ }^{52}$ Mary Mallon writes an adaptation from reports written by Harris. It discusses the many aspects of the darkroom project, including how photography was used by the Inuit participants. She includes several of their photographs, and credits them all by name. Features such as these offer insight into how Harris's work was received and discussed in mass media publications at the time.

Many of the features found in periodicals are photoessays compiled by Harris herself. Two such photoessays appear in This Magazine, which focuses on Canadian politics and the arts. They are entitled, "Mary Edetoak," 53 and "On the Land." ${ }^{54}$ Another piece, entitled, "Arctic Women" appears in the "Canadian Magazine For Women" Branching Out. ${ }^{55}$ Each piece features a selection of Harris's photographic work, paired with captions telling a bit of the story of the people in the photographs. They reinforce her commitment of documenting people's lives through the use of both words and images, giving a voice to the faces in the photographs.

\footnotetext{
${ }^{51}$ Ibid.

${ }^{52}$ Mary Mallon, "Photography at Spence Bay, N.W.T.," Focus Magazine (1975): 90-93.

${ }^{53}$ Pamela Harris, "Mary Edetoak," This Magazine 8, no. 3 (Aug-Sept 1974): 18-19.

${ }^{54}$ Pamela Harris, "On the Land: Photos and Text by Pamela Harris," This Magazine 10, no. 5 (Nov-Dec 1976): 24-25.

${ }^{55}$ Pamela Harris, “Arctic Women,” Branching Out (July-Aug 1976): 20-27.
} 


\section{CHAPTER ONE:}

\section{Pamela Harris and The Spence Bay Project}

Pamela Harris was born in 1940 in Erie, Pennsylvania, and moved to Toronto in 1967, when she was 27 years old. She has a Bachelors of Arts in English Literature from Pomona College in California, and is a self-taught photographer, having taken two workshops with the photographer Minor White, in 1970 and 1972. Harris's photographic work primarily focuses on the nature of communities. She captures the characteristics and identities of the many individuals who exist and participate in a particular geographical, social, or cultural space. The communities Harris chose to photograph were ones she felt warranted more attention than they were receiving, were worth creating a photographic document of, and would benefit in some way from the project. Between 1966 and 1975, Harris photographed in Ontario, Nova Scotia, Newfoundland, Quebec, New England, Kentucky, Czechoslovakia, Italy, France, and England. She is best known for her book and project entitled, Faces of Feminism, ${ }^{56}$ a collection of portraits representing the women's movement in Canada. Harris had each participant write a piece from their own perspective, since she wanted to avoid generalizing the community and allow her subjects "to speak for themselves."

Harris's work is in the permanent collections of several prominent institutions, including Library and Archives Canada (LAC), and George Eastman House (GEH) in Rochester, New York. She has contributed to numerous books, journals, and periodicals since the 1970s, and has taught at the Ontario College of Art and Design, Ryerson University, and Sheridan College, among others. From the 1970s through to the late 1990s, she also gave many lectures and

\footnotetext{
${ }^{56}$ Pamela Harris, interview by author, Toronto, ON, March 20, 2015.

57 Ibid.
} 
presentations across Canada.

In 2012, the Art Gallery of Ontario (AGO) acquired Pamela Harris’s Spence Bay collection. It includes 172 gelatin silver prints, consisting of unmounted photographic prints, as well as mounted prints from the exhibition entitled Spence Bay, N.W.T., which was shown at The Photographers' Gallery in Saskatoon, in 1975; The David Mirvish Gallery in Toronto, 1976; and in California's The Monterey Peninsula Museum of Art, in 1977. Additionally, the E.P. Taylor Research Library and Archives at the AGO hold the Pamela Harris fonds, including: textual documents such as correspondence, exhibition text panels, publicity and graphic material, 394 photographs, $135 \mathrm{~mm}$ film strip, 1 audio disc, 2 audio cassettes, and 4 audio reels. The 394 photographs include gelatin silver prints, contact sheets, and transparencies, created by both the darkroom participants and Pamela Harris.

The majority of Harris's images are portraits of women and men, both young and old, and children. They are photographed while carrying out various activities such as camping, carving, weaving, sewing, playing, exploring, dancing, sleeping, cooking, and fishing. Harris juxtaposes images that represent traditional Inuit life alongside those that represent a Southern influence. Another Way of Being (fig. 3) grew from the photographic work Harris produced while in Spence Bay, along with her research and interviews. It is comprised of 44 photographic reproductions and is divided into five sections: "Spence Bay," "Images," "A Conversation," "On the Land," and "The People." Another Way of Being combines text with imagery, a formal choice that Harris believes is essential to conveying multifaceted insights. She states that "words can capture more complex realities than images. Images give a kind of emotional sense of place and texture and person. But the complexities, I think are there more in the writing. And that's why for me, 


\section{Another Way of Being}

by Pamela Harris

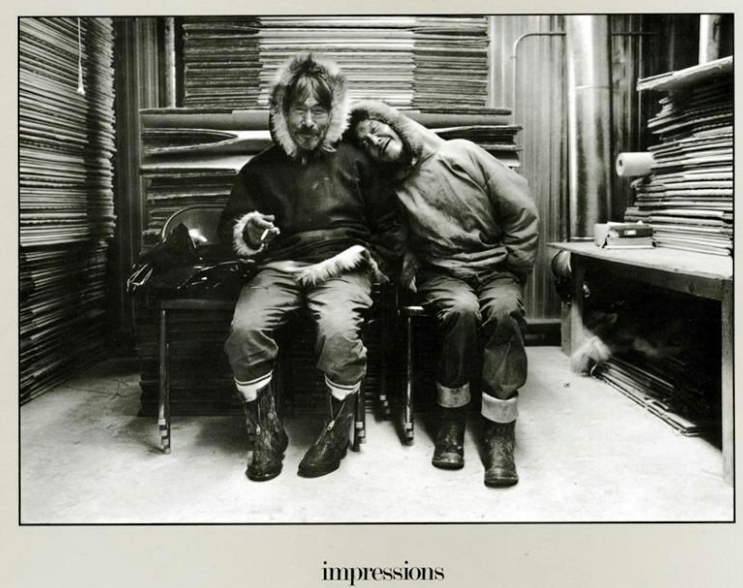

Figure 3. Another Way of Being, book cover. Photograph:

Tulurialik and Neeveeakchuk Waiting to Sell Carvings, 1972.

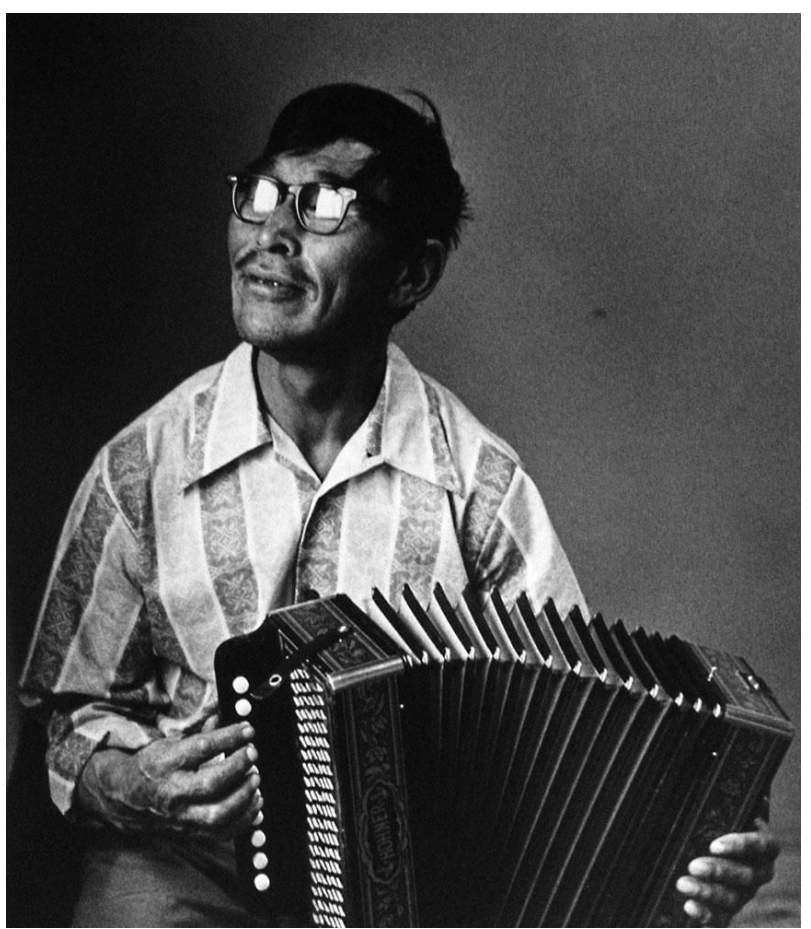

Figure 4. Joannie Saituk Playing Accordian, 1972/73. 
this project is words and images." people she met, ${ }^{59}$ highlights Harris's commitment to providing the Inuit a venue to tell their own stories, in their own words, alongside her own, with the photographs.

Subtle elements within the images are indicative of the dichotomy between Northern and Southern culture; sometimes the viewer must look closely to see them. For example, in the photograph Mary Edetoak (Old Mary) on her Bed, with Dolls (fig. 5) we see a woman sitting on her bed, where she works over a wooden plank to make dolls. The walls of the room are covered in floral wallpaper and various pictures, small decorations, a map, and a piece entitled, "The Lord's Prayer." Other elements indicate purchased Southern products, such as the box under her bed that reads "Fresh pasteurized milk," and on the floor, to the bottom left of the image, is a shopping bag that reads "The Bay." These elements may be subtle, but they are precisely the things that struck Harris so profoundly while in Spence Bay. She witnessed a way of life quite different from her own, one that she viewed as separate and unique from Southern traditions. At the same time, however, there were other visual cues familiar to her own culture: consumerism, mass produced factory made products, Christianity, etc.

In the photograph Children (in Woody Woodpecker Jackets) (fig. 6), we see four young boys posing together in front of the camera, uninhibited. The boy situated in the middle in the back has his arms outstretched around the boys to either side of him. Three of the boys are wearing jackets depicting Woody Woodpecker, a popular American cartoon produced by the Walter Lantz animation studio, and considered a Southern visual signifier. These children may or

\footnotetext{
58 Pamela Harris, interview by author, Art Gallery of Ontario, Toronto, ON, May 14, 2015.

${ }^{59}$ For an example, see discussion of figure 14 on page $35-36$.
} 


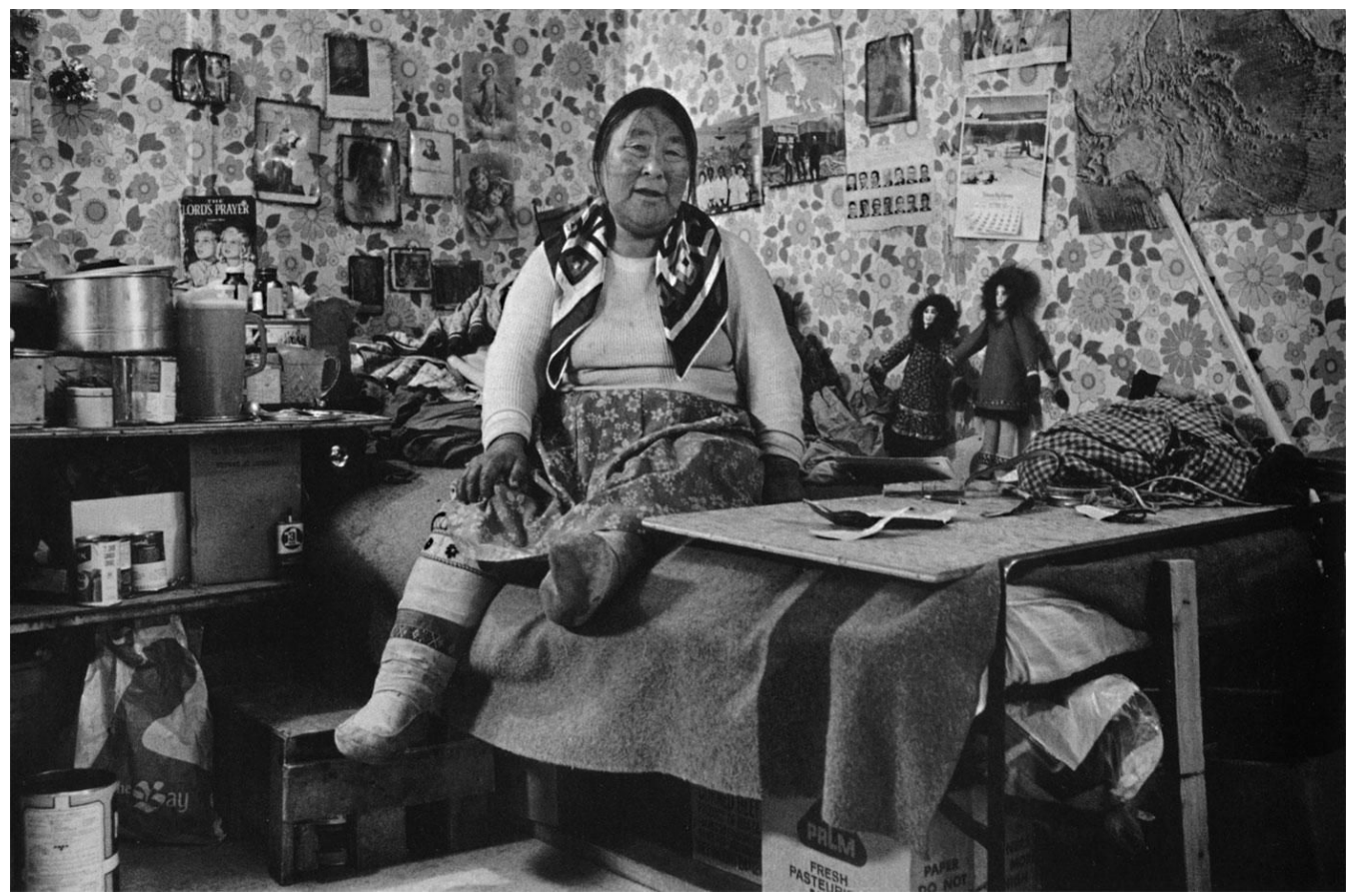

Figure 5. Mary Edetoak (Old Mary) on her Bed, with Dolls, 1972.

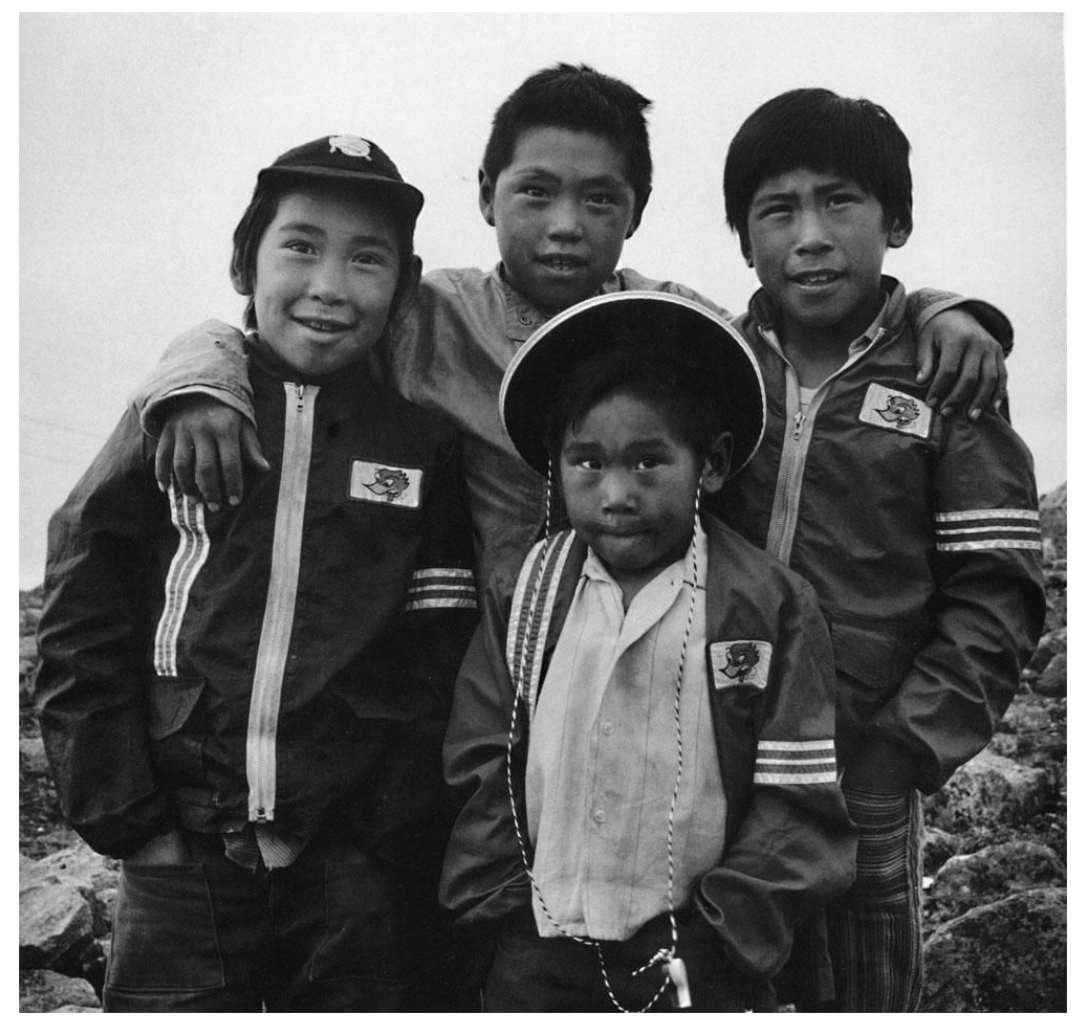

Figure 6. Children (in Woody Woodpecker Jackets), 1972. 
different." ${ }^{60}$ A more subtle example is the photograph entitled, Gemma Unalerk and Mailbag Tent, Netsilik River (fig. 7). At first glance, the photograph seems rather straightforward: an Inuit person standing in front of their tent, smiling, facing the camera, with hands clasped in front. It looks quite Northern. However, as the title indicates, the tent is made from a mailbag, brought to Spence Bay from another place and way of life, and resourcefully repurposed into material for a tent.

These images offer an alternative perspective from the imagery that dominates Indigenous visual culture, created by Southerners - images that depict subjects as objects, as specimens of a disappearing culture, sometimes devoid of context - and are indicative of how Harris's work differed from her predecessors. ${ }^{61}$ Her photographs often depict elements that are shared between Northern and Southern cultures. At the same time, one gets a sense of place in the photographs. There is a sense of personhood in them, an emphasis on the relationship between individuals, their environment, their pastimes, and their traditions. There is no monotony in choice of setting, person, clothing, or activity. The diversity of the Spence Bay community, in every respect, is captured by Harris. From incredibly intimate images, such as Family Sleeping (Cambridge Bay) (fig. 8), to ones more formally composed, such as Joannie Saituk Playing Accordian (fig. 4). The face is particularly prominent (fig. 9, 10), and Harris explains, "For me, I love it when I get an eye connection, because I love it when people look at one another, and the soul flows out, I don't believe in souls but you know what I mean, the being of the person."

\footnotetext{
${ }^{60}$ Harris, interview, March 20, 2015.

${ }^{61}$ Harris was familiar with both Flahery's and Harrington's work. She describes the book, The Family of Man, in which Harrington's work appears, as, “...my first photographic teacher.” Pamela Harris, e-mail message to author, July 29, 2015.

${ }^{62}$ Harris, interview, May 14, 2015.
} 


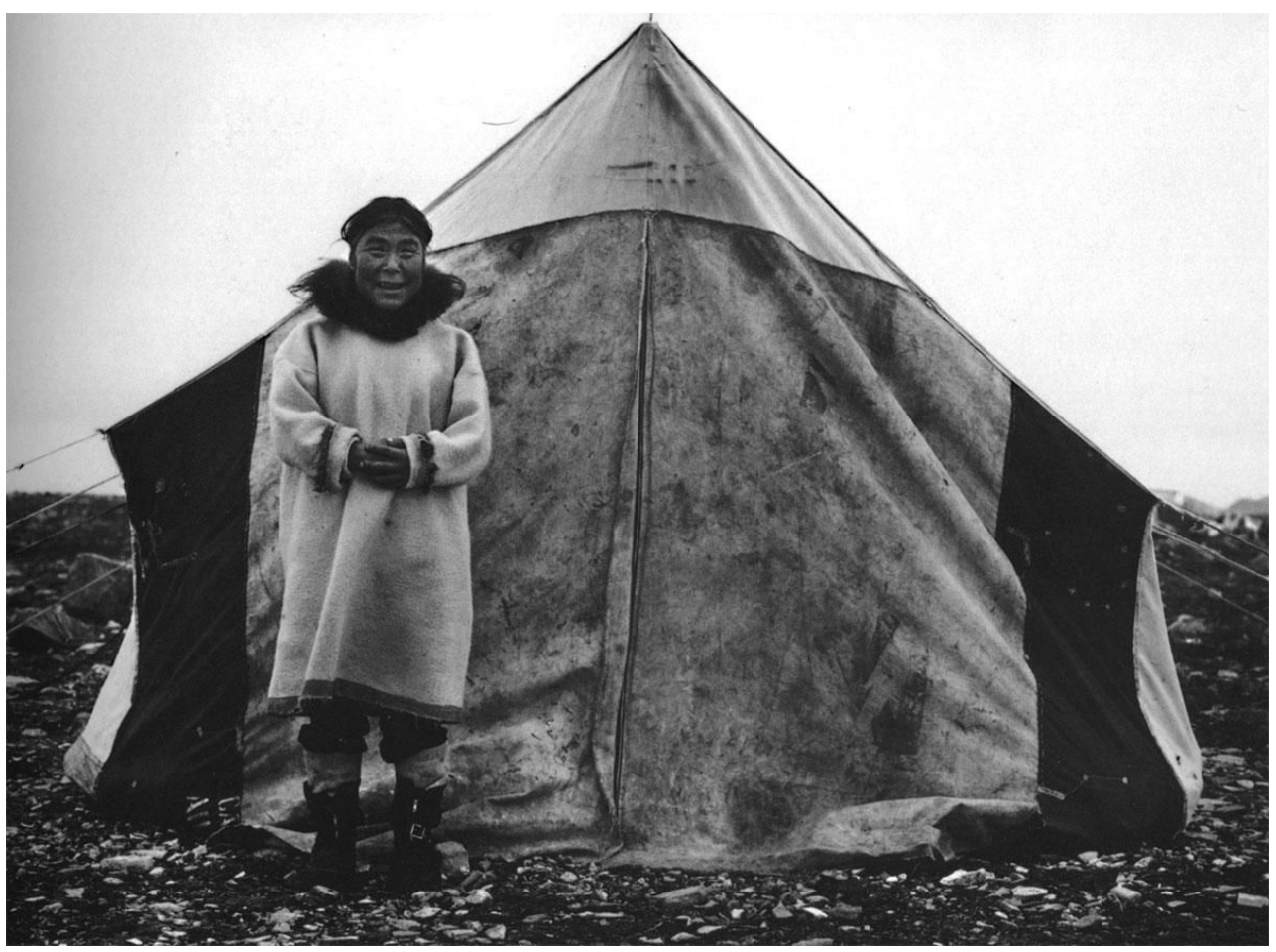

Figure 7. Gemma Unalerk and Mailbag Tent, Netsilik River, 1973.

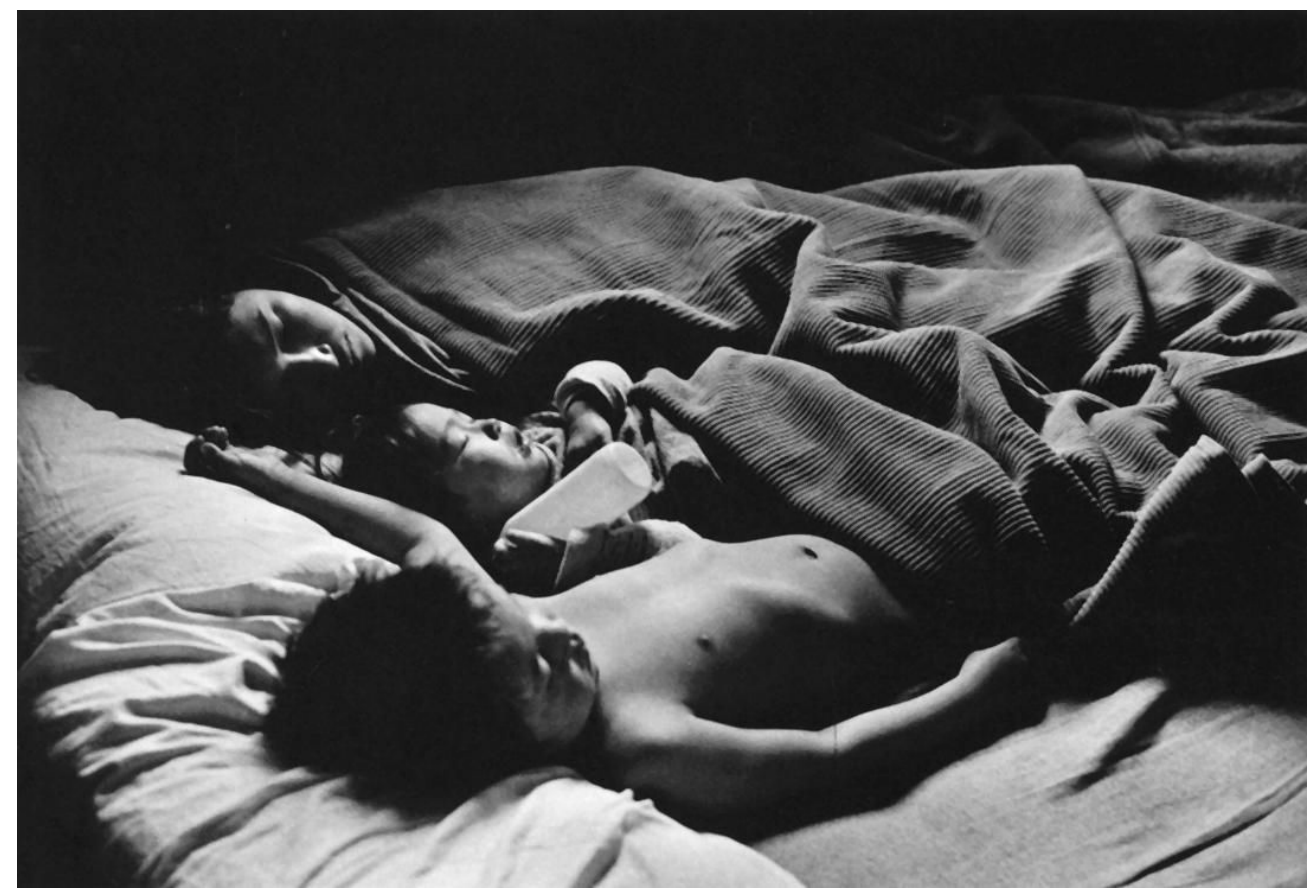

Figure 8. Family Sleeping (Cambridge Bay), 1973/73. 


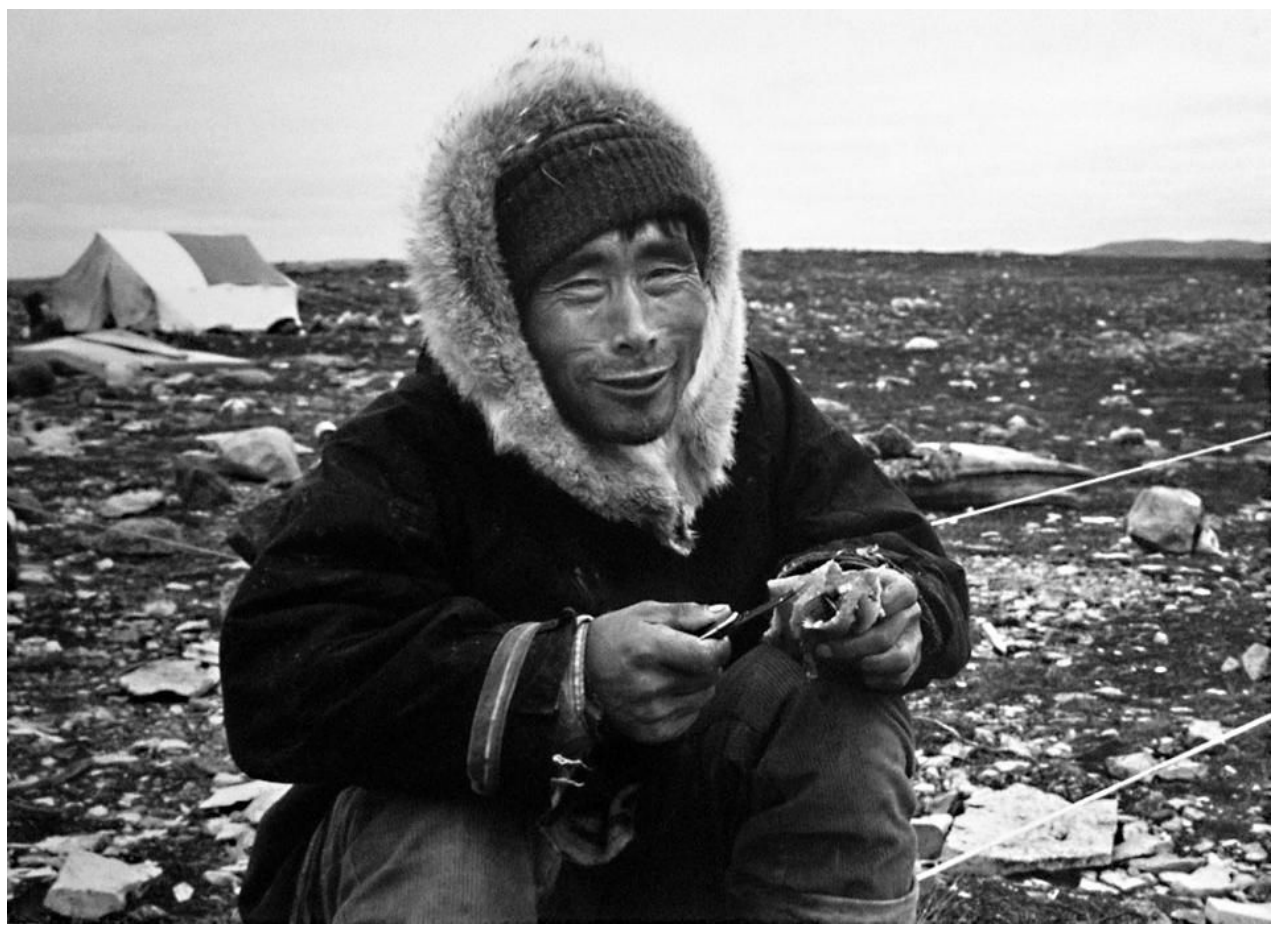

Figure 9. Jude Iqalliyuq, 1972/3.

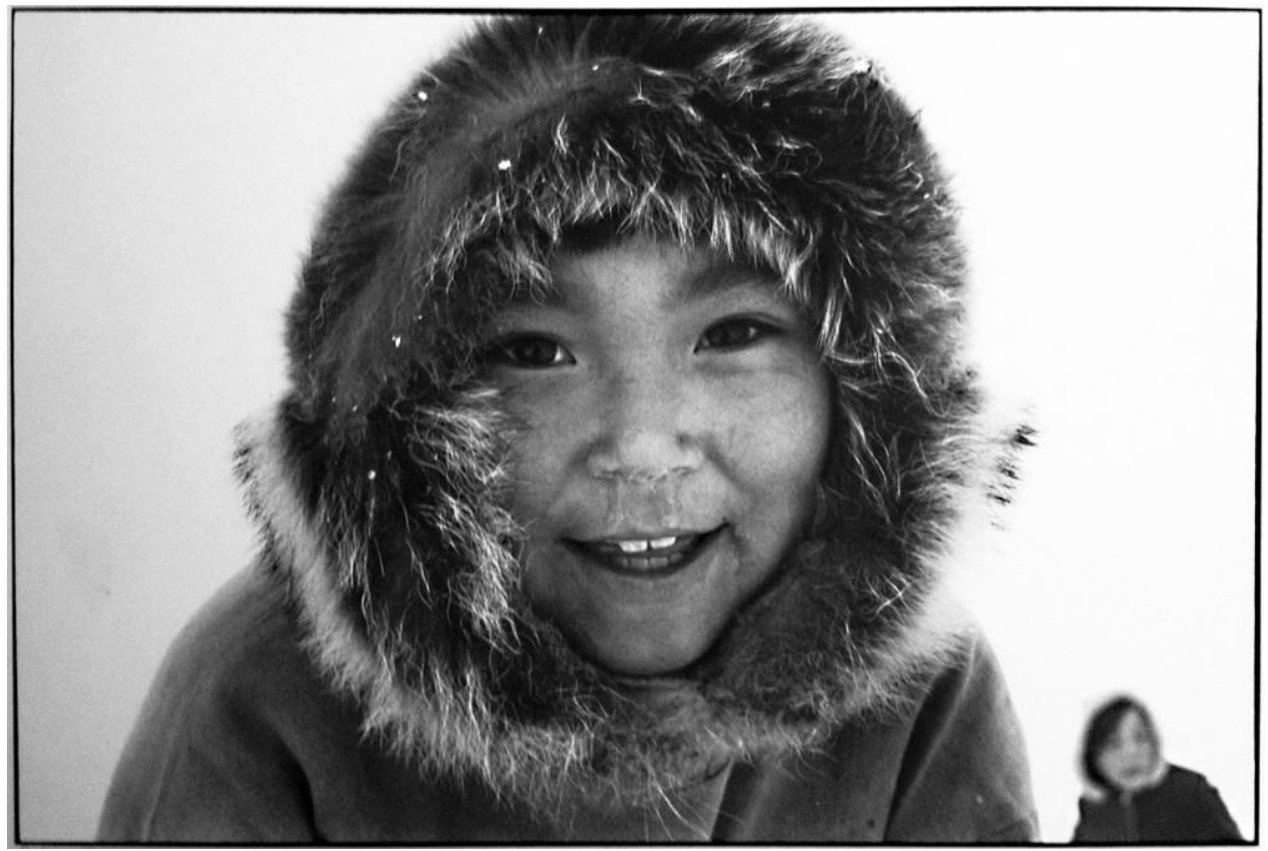

Figure 10. Pauloosee Jayko (The Day the Boat Came In), 1972/73. 


\section{CHAPTER TWO:}

\section{The Photographs - Particulars of Place and Approach}

\section{Why Spence Bay}

Spence Bay (fig. 2 \& 11) was an Arctic community rooted in traditional Inuit culture, comprised of Netsilik and Dorset people, who speak Inuktitut. ${ }^{63}$ At the time of Harris's first visit in 1972, she observed a community in transition; a community becoming increasingly influenced by Southern culture. ${ }^{64}$ As she looked around with open and curious eyes, she continuously saw Northern and Southern aspects juxtaposed in the same environments, stating that you didn't even need to look for the cultural melange, it was everywhere. ${ }^{65}$ However, it was not that one way of life was vanishing because of another, but that these Northern and Southern ways, were now coexisting.

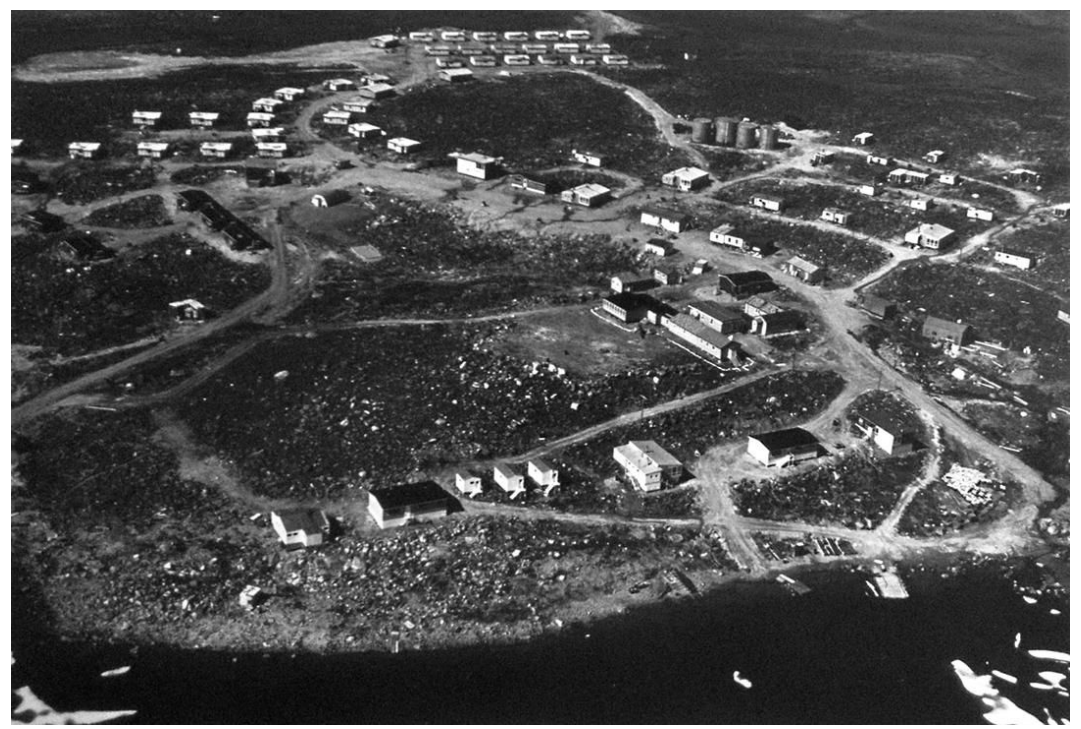

Figure 11. Spence Bay from the Air, 1972/73.

\footnotetext{
${ }^{63}$ Marilyn Nazar, and Molly Kalkstein, "Description and Finding Aid" [2013] Pamela Harris Papers, E.P. Taylor Research Library and Archives, Art Gallery of Ontario, Toronto, p. 2.

${ }^{64}$ Harris, Another Way of Being, 4.

${ }^{65}$ Harris, interview, May 14, 2015.
} 
Harris went to Spence Bay largely due to circumstance. While exploring Newfoundland, Harris met the artist Judy McGrath (fig. 12), whose husband was employed by the Canadian Arctic Producers, who purchased whale bone carvings made by the Inuit in Spence Bay. ${ }^{66}$ Harris recognizes that she would never have gone to Spence Bay if McGrath had not already been up there. She explains: "I only did that project for one reason, it's pure serendipity. I would never have had the guts, or even thought I should, go to a little community like that, if I didn't have a connection. It is because I met Judy, it's 'cause we connected strongly, it's 'cause she was going up there..." ${ }^{67}$ Moreover, McGrath's presence offered an entryway into the community. Instead of arriving as a complete stranger, Harris's ties to McGrath made her a de facto friend of Spence Bay's inhabitants. ${ }^{68}$ After her first trip, Harris realized that she was drawn to the community, and decided on a return visit. ${ }^{69}$ But this time, with a greater purpose.

Due to the remoteness of Spence Bay, Harris recognized that many people in the South had no idea of what life was like in this small Northern community. So few people lived or travelled there, but Harris believed it was important to capture their lives and share it with communities elsewhere. It was a means by which the Inuit could have a presence outside of their own community, to be both seen and heard in contemporary society, and contribute to a historical record. The question confronting Harris was how to depict Spence Bay. How does one represent a community that has historically been represented as "other"-what photographic approaches will portray the residents of Spence Bay in a way that does not reinforce Indigenous stereotypes?

\footnotetext{
${ }^{66}$ Harris, interview, March 20, 2015.

${ }^{67}$ Ibid.

${ }^{68}$ Pamela Harris to Judy McGrath, 24 June 1972, Series 1, file 1-8, Pamela Harris Papers, E.P. Taylor Research Library and Archives, Art Gallery of Ontario, Toronto.

${ }^{69}$ Harris to McGrath, 8 February 1973, Series 1, fol. 1-9, Pamela Harris Papers.
} 


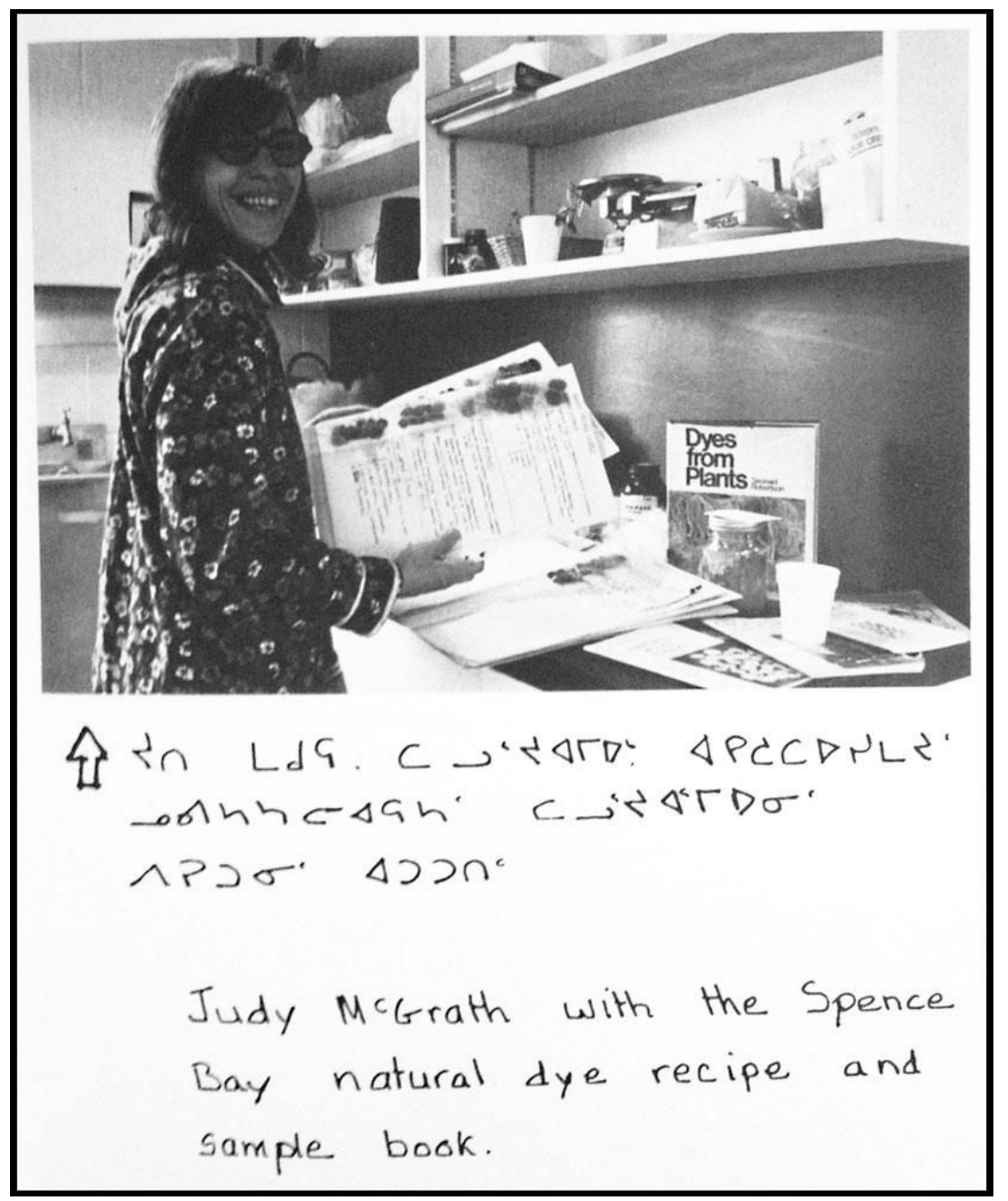

Figure 12. Judy McGrath with the Spence Bay Natural Dye Recipe and Sample Book, in Arctic Women's Workshop, 1974. 
The situation in Spence Bay helped Harris realize that this was a unique moment in history, Southern culture was changing the traditional Northern way of living; it was transforming Inuit culture. Everywhere she looked, Harris observed visual elements that she associated with Inuit culture coupled with elements that were familiar to her from Southern society. As a documentary photographer, she wanted to create photographic records of this phenomenon — visual documents that captured chosen moments in time - an embodiment of both photographer and subject. She states: "what I recorded when I went to Spence Bay, is gone. TV, internet, Southern culture, has totally washed over it, the North, for better or worse. So this is a document, however incomplete, of a community at a certain point in time. How the people were then. And I think it's tremendously important, that we keep our history, because otherwise the future rewrites it." The "our history" that she refers to is the collective "us,"- - not just in Canada, but applicable everywhere - and highlights how photographs serve as a means to secure certain aspects of history in visual documents, a role that Harris's photographs soundly accomplish.

\section{Community Engagement \& Inuit Representation}

Harris was conscious of being a guest within the Spence Bay community, and her position as such led to careful self-examination of her photographic approach and its impact on the community. Many photographers who travel into different and unfamiliar communities are outsiders. However, it is how one approaches their photographic work that is important: their interaction with their subjects, the context of their representation, and the resulting photographic images.

\footnotetext{
${ }^{70}$ Harris, interview, March 20, 2015.
} 
When a non-Indigenous person photographs an Indigenous community, questions and considerations arise, for both photographers and scholars, regarding how one represents others in photographic work. For photographers who encroach on the space of the other, one might ask: What has changed, if anything, when a non-Indigenous person photographs in an Indigenous community? What purpose do the photographic images serve? What are the intentions and the perspective of the photographer? What background experiences influence how one creates photographic work? Did Harris's link to feminism and the women's movement influence her photographic approach? Did her gender change anything? How does this alter Indigenous representation in photographic work?

To highlight the importance of these questions, one must consider the perspective of Indigenous individuals. For example, Iroquoian artist and curator Jeffrey Thomas discusses his encounter with photographs of Indigenous people in archives, and states: "I found pictures by white photographers who seemed to have an overwhelmingly singular preoccupation with photographing Indian warriors and chiefs. I felt that the photographic archive should reflect the reality of Aboriginal people, depicting all the members of our societies in everyday settings, rather than single out one aspect of our culture and history." ${ }^{71}$

Harris's approach to creating photographic work is indeed influenced by her own experiences. Her involvement in social justice causes, such as the anti-Vietnam war movement, often incorporated photography. ${ }^{72}$ This work helped her develop the ability to analyze the world around her, and be politically conscious of the responsibilities inherent to image making. Given the social-political context of the 1960s and 1970s, it is important to question Harris's approach

\footnotetext{
${ }^{71}$ Payne and Thomas, "Aboriginal Interventions into the Photographic Archives," 110.

${ }^{72}$ Harris, interview, March 20, 2015.
} 
to creating photographic work of Indigenous others, the social responsibilities such work entails, and the impact this has on the lives of others.

Harris describes her use of photography as a window, rather than a mirror. ${ }^{73}$ She did not seek to produce photographs about herself, but wanted to photograph the things she saw around her, and, in particular, to celebrate the ordinary. ${ }^{74}$ This is why communities have been central to her work, in order to honour the unique and varied individuals that communities are comprised of. Early on in her career, Harris photographed a number of communities in the United States and Canada. They were not always geographically defined, but rather aligned through social

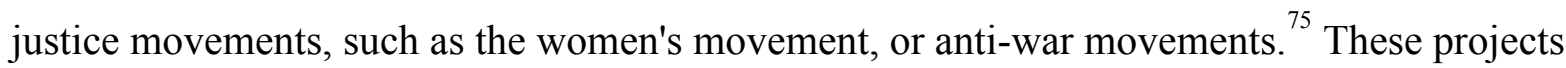
illustrate her interest in the social aspect of the communities she chose to photograph. The relationship between photographer and the community being photographed is of particular significance. Engaging with community members and focusing on their participation in the creation of the photograph alters its social context. No longer is it merely an image taken of someone, but one created with them.

Firstly, it was important for Harris to communicate her intentions with the Spence Bay community. She states: "If people know why you're photographing, ... if you have a reason, [and] you're not just clicking because you think you get to run away with their faces," illustrates

\footnotetext{
${ }^{73}$ This is in reference to John Szarkowski's exhibition at the Museum of Modern Art (MoMA) in New York, and accompanying book, entitled Mirrors and Windows: American Photography since 1960 (1978). Harris did not see the exhibition but was aware of it and the ideas behind it, which suggests that "...there is a fundamental dichotomy in contemporary photography between those who think of photography as a means of self-expression and those who think of it as a method of exploration." John Szarkowski, Mirrors and Windows: American Photography since 1960 (New York: The Museum of Modern Art, 1978), 11.

${ }^{74}$ Harris, interview, March 20, 2015.

${ }^{75}$ Ibid.
} 


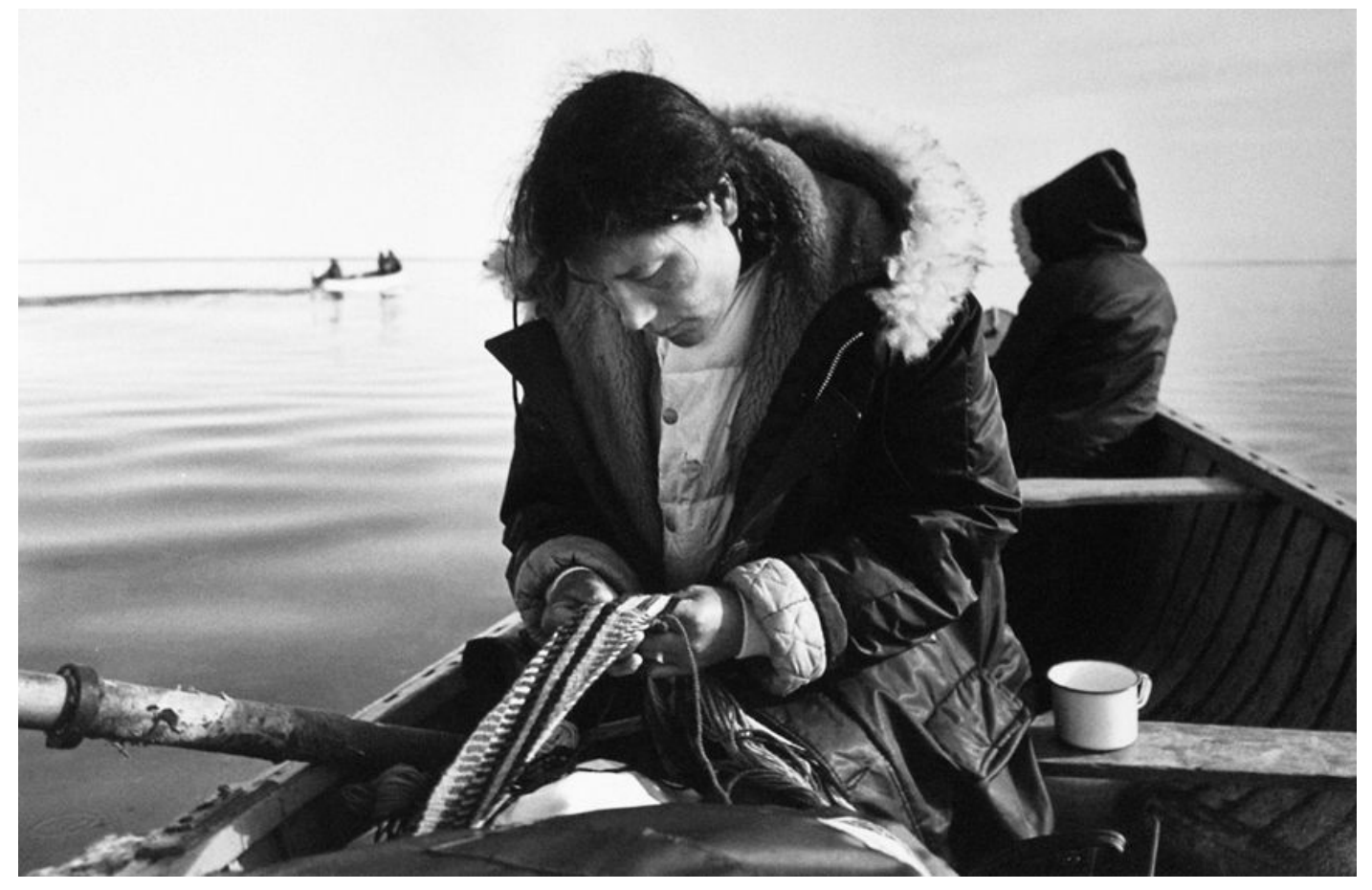

Figure 13. Nilaulaq Fingerweaving on the Way to Netsilik Camp, 1973.

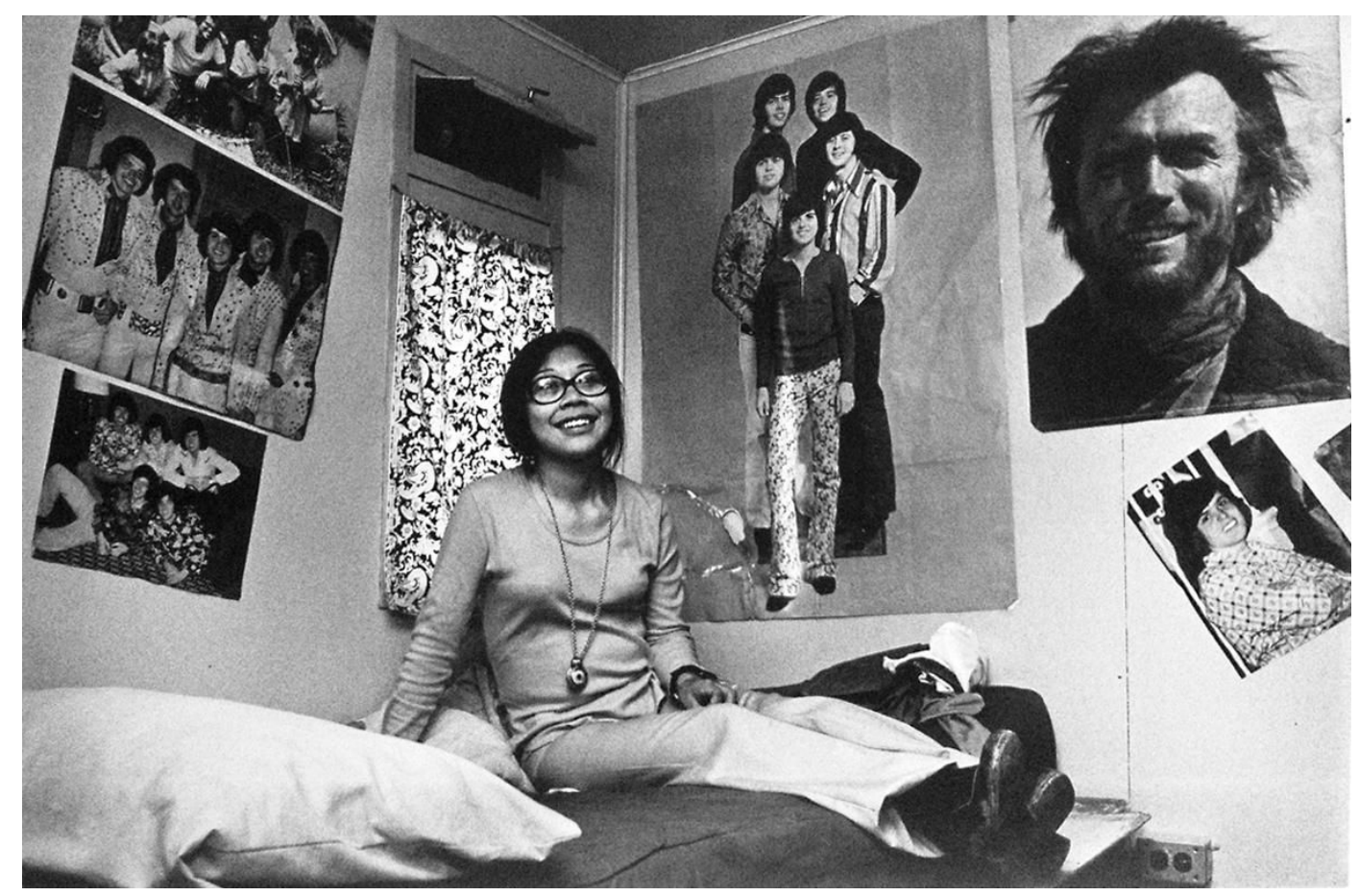

Figure 14. Mary Neeveakcheak in her Room (Posters), 1973. 
her concern for the power dynamic that can emerge between the photographer and the photographed. $^{76}$ Since she respects people as equals, Harris was committed to a non-hierarchical exchange, putting into practice the ideals embedded in feminist theory. By communicating why she was there, what she planned to photograph, and how the images were to be used, she created a space for dialogue. It allowed for the community to respond, and encouraged a relationship of trust to develop.

Harris captured people in their natural environments, in everyday situations, rather than in isolation from them. As Jeffrey Thomas points out, this was one of the things that was missing from the Indigenous photographs that he encountered. Similarly, Susan Close notes that eliminating the social context contributes to the objectification of the subject, and is "also used to as a strategy to assign otherness. ${ }^{, 77}$ In Harris's photographs, everyday situations present a diverse range of contexts, including those portraying traditional Inuit culture, as well as those portraying a Southern cultural influence. A variety of interior and exterior landscapes are depicted, documenting what is both foreign and familiar to a Southern audience. For example, in Nilaulaq Fingerweaving on the way to Netsilik Camp (fig. 13), we see Nilaulaq, in a boat, wearing a parka. She is not making eye contact with the viewer, but is instead looking downward, focusing on her weaving. The image is taken outdoors, on the water, and is captured in a natural setting. It is neither staged nor posed. On the other hand, in the photograph Mary Neeveakcheak in her Room (Posters) (fig. 14), we see a young girl who is sitting on her bed in her bedroom. She is leaning on one arm, looking slightly away from camera and smiling - she seems relaxed. Several

\footnotetext{
${ }^{76}$ Harris, interview, May 14, 2015.

${ }^{77}$ Close, Framing Identity, 57, 58.
} 
posters hang on her bedroom walls, depicting movie and pop stars. ${ }^{78}$ Text from Another Way of

Being offers additional information to what and who the photograph depicts:

Eeteemunga agrees to teach me four-strand braiding. I go to her house and we drink tea. She is braiding such fine strands of sinew that I'm afraid I won't be able to learn. We have no language except for our eyes; hers are very kind, full of life. We kneel on the floor and she struggles to teach my fingers what to do. When they finally learn, I feel very happy and close to her. Later her teenage daughter comes in, one of the generation who left the camps to go to school in Inuvik. She is gentle and shy. Her English seems unsure, but she tells me she speaks better in English than in Inuit. She has never learned four strand braiding. She shows me her room, the walls covered with posters of pop singers and a table covered with bottles of perfume and cosmetics. ${ }^{79}$

If it was not made clear where this photograph had been taken (in the bedroom of an Inuit community), it almost seems as though it could have been taken anywhere in Western society. ${ }^{80}$ This emphasizes mass media's ability to both reach and appeal to people of radically different cultures. As another example, a landscape image of industrial storage tanks, with small climbing figures (fig. 15), is juxtaposed, in a spread, against an image of a child in a parka running in a beautiful snowy Arctic landscape (fig. 16). The images taken at a distance are meant to create a sense of place, through depictions of landscape, and in Another Way of Being are always displayed alongside more intimate images. Harris uses juxtaposition and diversity to show the viewer two simultaneous pictures of Spence Bay. Firstly, she shows what is expected, reinforcing certain stereotypes. Secondly, and more importantly, she shows what may not have been, which challenges expectations.

\footnotetext{
${ }^{78}$ The posters on the walls depict actor Clint Eastwood, and the musical group The Osmonds, among others. Pamela Harris, e-mail message to author, July 29, 2015.

${ }^{79}$ Harris, Another Way of Being, 7.

${ }^{80}$ Harris, interview, May 14, 2015.
} 


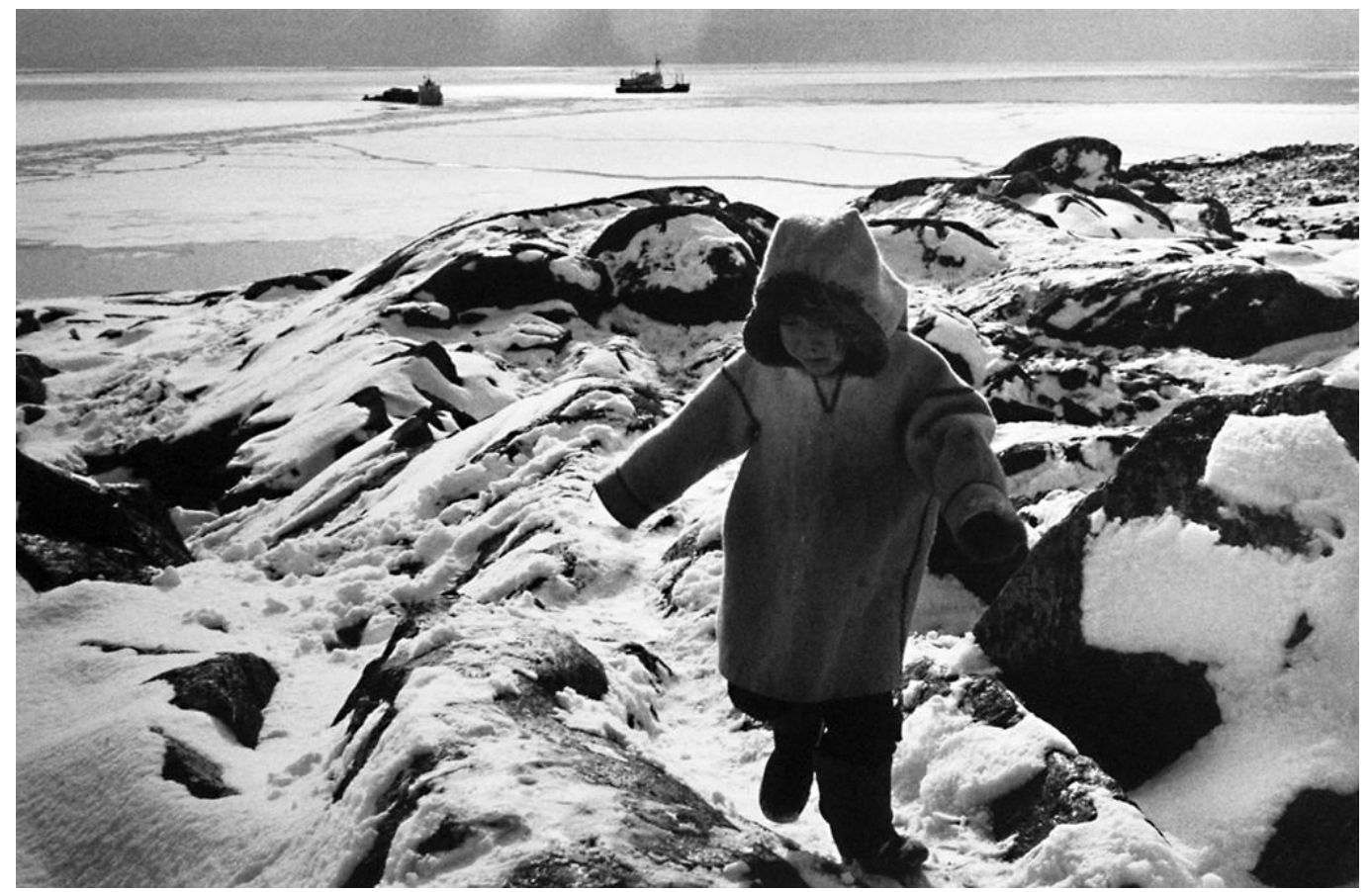

Figure 15. Pauloosee Jayko (The Day the Boat Came), 1972/73.

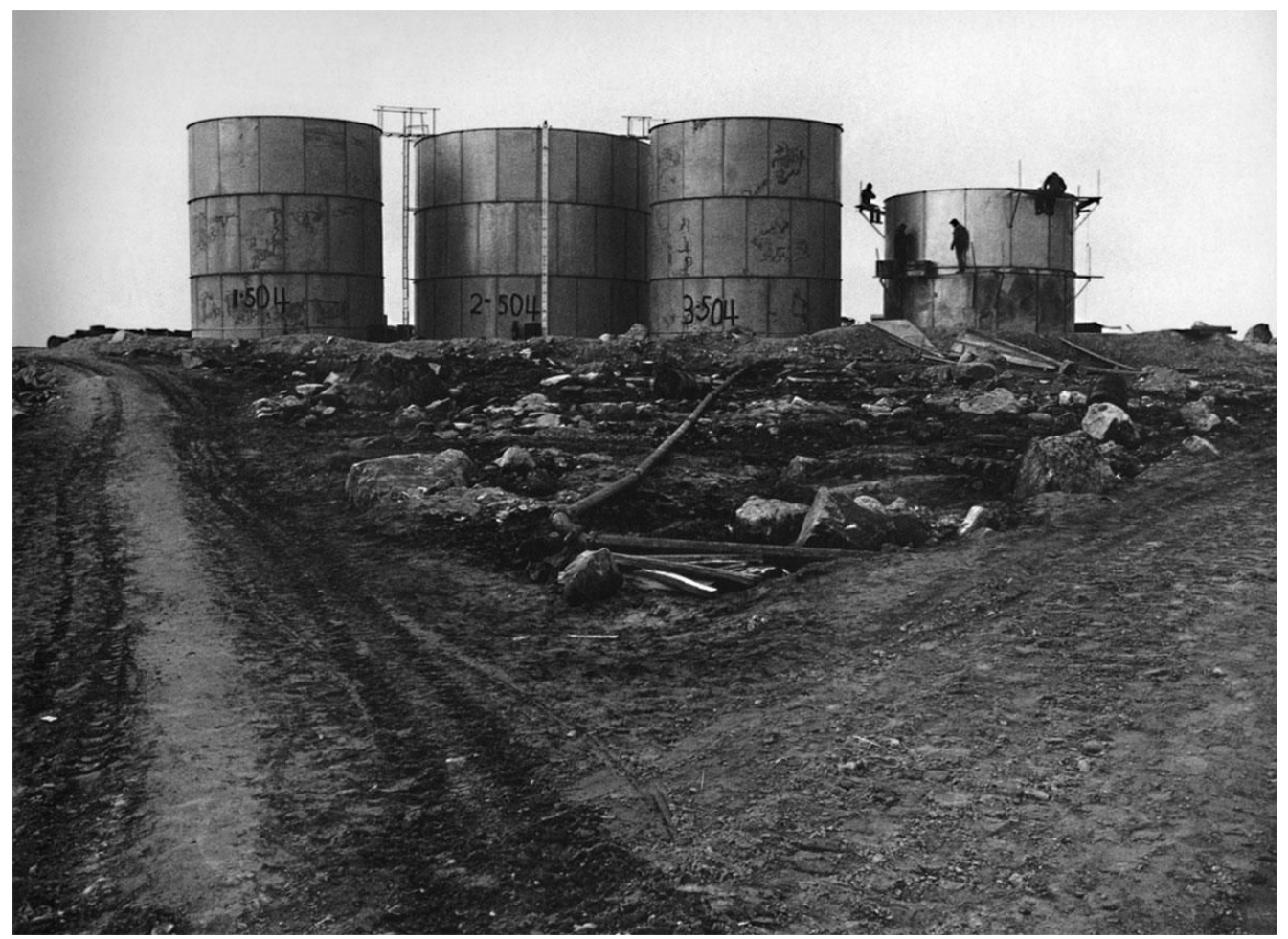

Figure 16. Storage Tanks, 1972. 
For Harris, photography is a tool used to engage with her subjects, and one that they could participate in together. ${ }^{81}$ She was not interested in passively taking photographs that were detached and superficial, but close, personal, and intimate; communicating her intentions, getting to know her subjects, listening to their stories, and creating a trusting friendship with them. Having a good relationship with people was, in some ways, more important to Harris than creating beautiful photographs. ${ }^{82}$ By doing so, the practice becomes something that people are involved in together, which dispels the latent power dynamic. She states: "if you feel shy about getting in there and engaging without photographing, or photographing without engaging, that's a good feeling because it implies that you are aware of the possibility of a power struggle/ relationship, or you're aware of the power of what you are doing, and then you can be sensitive to those people, and you're going to get better pictures, I think that's true." ${ }^{83}$

Photography was a means for Harris to collect the stories and experiences that she felt were integral to the people within them. It was "the livingness in things" She was not seeking to capture images as objects to be looked at, or owned, but as a record of social interactions that conveyed the lived experiences of the subjects within them. In a letter to Judy McGrath, she writes: "It's related to everything I've been saying to you about the trip to Spence crystallizing certain feelings about photography: you all gave me energy to print just by being in the pictures, because the audience I'm interested in this time is you all... the people in the pictures. The other audience can come along too, but they don't matter. The image as object is less important.... If the life that is in Spence is reflected at all in the photographs, I'm happy,

\footnotetext{
${ }^{81}$ Harris, interview, March 20, 2015.

${ }^{82}$ Harris to McGrath, 2 November 1972, Series 1, fol. 1-8, Pamela Harris Papers.

${ }^{83}$ Harris, interview, May 14, 2015.

${ }^{84}$ Harris, interview, March 20, 2015.
} 
they do what I think they should do... ${ }^{85}$ The stories connected to the images are integral. The community is not just the subject of the photograph, but a part of its production and existence. This is why the inclusion of text with the images is necessary, and desired, and helps to define Harris as a documentary photographer. When speaking about Another Way of Being, she states: "I don't think people looked at this as a photo and text book, you cannot figure out what this book is about just by looking at the pictures, you have to read this, because there are things that are not in these pictures, that are here in the writing, and for me the absolute key to the whole thing is the conversation with... 'Jude, ${ }^{, 86} \ldots$ I think it's the essence of the whole book, the tension between things is in what he has to say..." 87 Jude is an Inuit Harris interviewed. The "key," as she describes it, are his feelings toward the cultural changes he is observing and experiencing. There is a sense of him feeling torn between two worlds, a dissatisfaction towards this, and a sadness (see excerpt in Appendix C).

Harris's interest in, and the connection she felt toward, the community of Spence Bay gave her the ability to create intimate portraits of people and landscape, both in the town and on the land. The photographs show the subject's connection to their craft, their environment, their community, their family, and to Harris. Subjects are not isolated from their environments, and the viewer gets a sense of the surroundings and happenings of this place. She succeeded in capturing the everyday experiences and variety of activities (fig. 17, 18) that she witnessed and participated in while at Spence Bay; images of a time, place, and way of life that was unique to that moment.

\footnotetext{
${ }^{85}$ Harris to McGrath, December 1972, Series 1, fol. 1-8, Pamela Harris Papers.

${ }^{86}$ Jude is not his real name. Harris, interview, March 20, 2015.

${ }^{87}$ Harris, interview, March 20, 2015.
} 


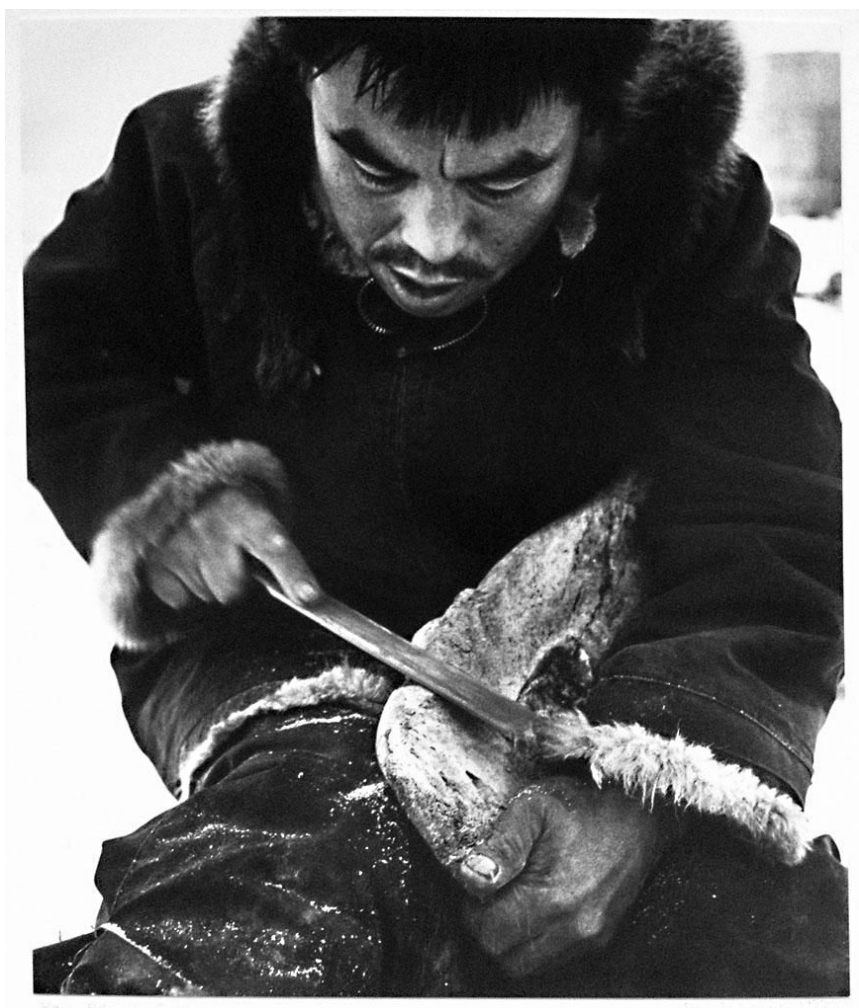

Figure 17. Karoo Ashevak Carving, 1972/73.

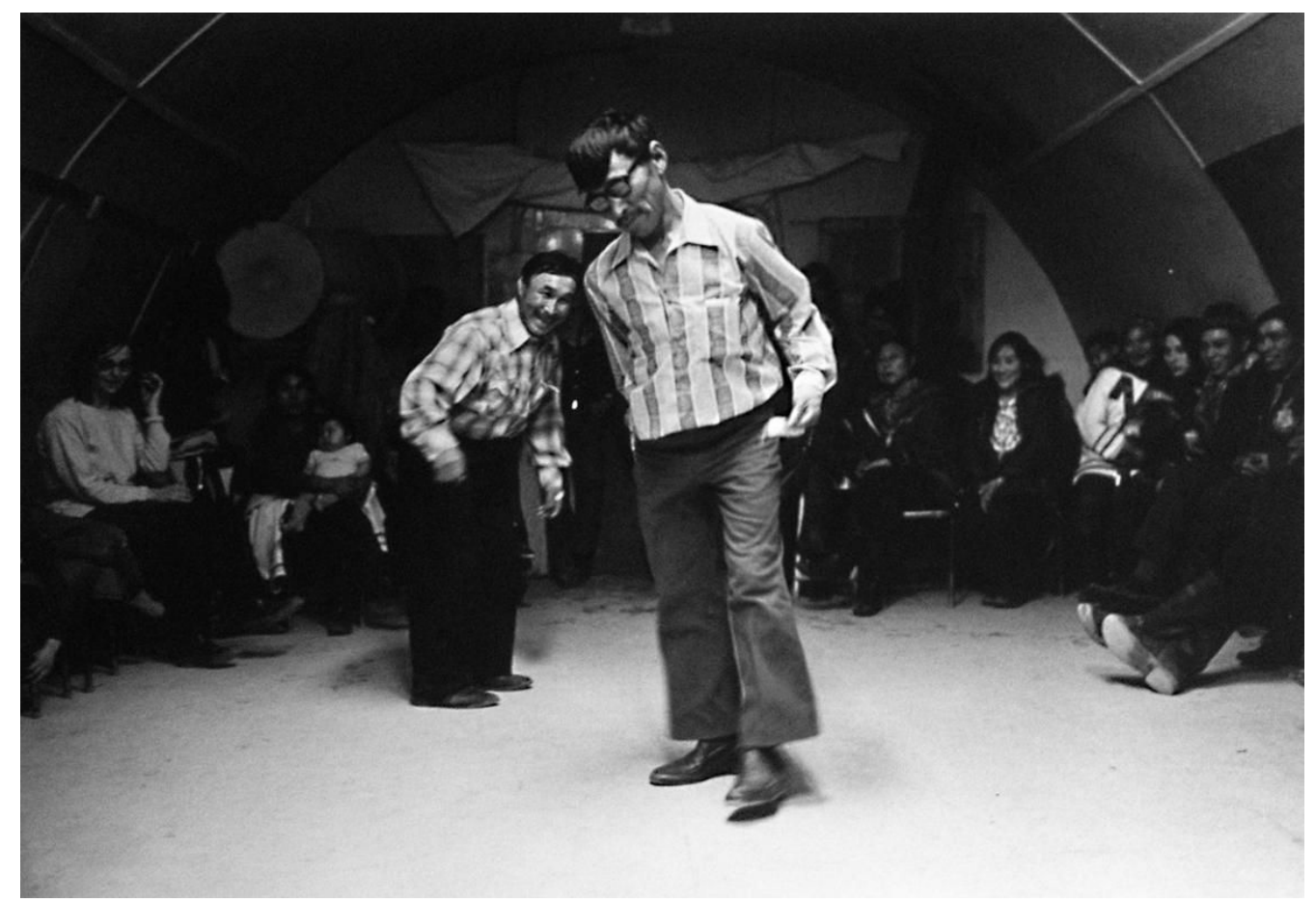

Figure 18. Napachee Kallak and Joanie Saittuq Stepdancing, 1972/73. 
Historically speaking, the majority of Indigenous people depicted in photographs have been portrayed nameless, often identified simply as, 'Eskimo woman. ${ }^{88}$ Carol Payne explains that naming has significant meaning in Inuit culture, and that "Three essential parts made a human in the Inuit view: body, soul, and name. A nameless child was not fully human..." Names serve to embed photographs with a specific individuality, and a unique perspective. Not doing so runs the risk of representing people as "interchangeable racial types. ${ }^{90}$ Harris was adamant about recording people's names. She mailed some of her photographs to Spence Bay, as gifts, but to also obtain or correct the names of people in the photographs. ${ }^{91}$ This act illustrates her commitment to capturing their individual identities, which sets her apart from her predecessors. Harris was not attempting to pose as an insider, but strived to behave as a socially conscious outsider, something many failed to do before her. Each individual is presented with a specific name and identity, unique in the community yet collectively bonded. In addition to this, the titles accompanying the photographs often indicate the activity taking place, such as fingerweaving, playing the accordion, or stepdancing. Descriptive titles that reference activity help to convey a sense of place, an important element in garnering a sense of the subject's identity.

Harris's involvement with the women's movement coincides with her work on "The Women's Kit"92 while working at the Ontario Institute for Studies in Education (OISE). A parallel can be drawn between the representation of Indigenous people in photography, and the

\footnotetext{
${ }^{88}$ Payne, The Official Picture: 175,

${ }^{89}$ Ibid., 186.

${ }^{90}$ Payne, "Through a Canadian Lens," 436.

${ }^{91}$ Harris to McGrath, 28 January 1973, Series 1, fol. 1-9, Pamela Harris Papers.

${ }^{92}$ An educational multimedia kit geared toward young women. For a more in depth discussion of "The Women's Kit," see Chapter Three: The Darkroom Project.
} 
representation of women. Harris, as a woman and feminist, created photographic work that did not objectify. Historically, there have been several women that photographed Indigenous communities, often associated with a studio or an anthropological organization. The significance of Pamela Harris being a woman, is that she came of age as second-wave feminism was emerging, offering new and analytic perspectives on the lives, roles, and representation of women. This no doubt influenced her a great deal, as she identifies as a feminist, and did so at the time of the Spence Bay project. 


\section{CHAPTER THREE:}

\section{The Darkroom Project}

Following her first trip to Spence Bay, Harris immediately began to think of reasons to return. On her second visit, however, she wanted to offer something useful to the community, in return for welcoming her as a guest in their homes. Harris writes: "There is a question that continually bothers me when I'm photographing, particularly in a place I like as much as Spence Bay: of what use is my photographing to these people? Am I just using them? There's much talk about the honest record, ${ }^{93}$ but of what use is the record to the people? ... I would like to evolve a way in which the process of being photographed would be meaningful to the people I photograph. In other words, I would like to be able to use the process of recording as a consciousness raising tool for the subject...",94

The next step after photographing the community, was naturally, to connect the community with photography. The result was the Spence Bay darkroom project. She states: "I kept feeling parasitical $[$ sic $]$ — until I decided that the one thing I had to offer them was the skill of developing and printing their own photographs themselves." ${ }^{95}$ Teaching darkroom techniques would encourage the Inuit community of Spence Bay to document their own lives and create their own visual history. It was a practical tool that could continue to be used into the future.

\footnotetext{
93 The "honest record" is in reference to social documentary photography, or photographers wanting to make a difference, as Harris puts it. Harris also refers to the Farm Security Administration (FSA), in relation to this statement, as Harris wanted to "make photographs useful to the people she documented." Pamela Harris, e-mail message to author, July 29, 2015.

${ }^{94}$ Pamela Harris, "Photographic Documentation Project" [April 1973], Series 2, file 2-12, Pamela Harris Papers, E.P. Taylor Research Library and Archives, Art Gallery of Ontario, Toronto, p. 3.

95 Dault, "Photography Helps Inuit Control Changing Culture," 1976.
} 
The late 1960s and early 1970s was an era that embraced freethinking and self-initiated projects. As Harris explains, if one wanted to start a project, one just went ahead and did it: "Somehow, there was so much young energy... things seemed more possible.... There was a whole movement of starting free schools, talking about education... all kinds of issues... there was cultural foment... of course it all starts with the civil rights movement and Vietnam... there was a lot of different ways of thinking about things, in the sense that if you wanted to start a gallery, you just started a gallery, and if you wanted to put out a magazine, you put out a magazine." ${ }^{96}$ There was a strong sense of self-empowerment, and this mentality influenced Harris in her vision of the darkroom project.

After much planning and correspondence between herself and McGrath, Harris returned to Spence Bay in 1973. This time she stayed for three months. She brought darkroom supplies and equipment, funded by the support of several organizations: the Department of Economic Development of Northwest Territories (who provided money for equipment), Kodak Canada Limited (who supplied materials), The National Film Board (NFB) of Canada, and the Canada Council. $^{97}$

The Darkroom (fig. 19, 20, 21, 22) was set up in the local women's craft shop - a location chosen because "it is the centre of activity for the women and... a place that belongs to the people who work there." ${ }^{98}$ The craft shop was established by McGrath, who was conducting dye workshops. ${ }^{99}$ It took over a month to set up the darkroom, partly because of certain things taken

\footnotetext{
${ }^{96}$ Harris, interview, March 20, 2015.

${ }^{97}$ Pamela Harris, "The Spence Bay Darkroom" [December 1973], Series 2, file 2-12, Pamela Harris Papers, E.P. Taylor Research Library and Archives, Art Gallery of Ontario, Toronto, p.1.

${ }^{98}$ Mallon, "Photography at Spence Bay," 91.

${ }^{99}$ Judy McGrath, "started a women's craft project in which the women work on the adaptation of traditional styles and techniques into contemporary design... [and ran] the first Northern natural-dye workshop, investigating, developing, and teaching native people the natural-dye potential of Northern plants. Harris, "Photographic Documentation Project," 3.
} 


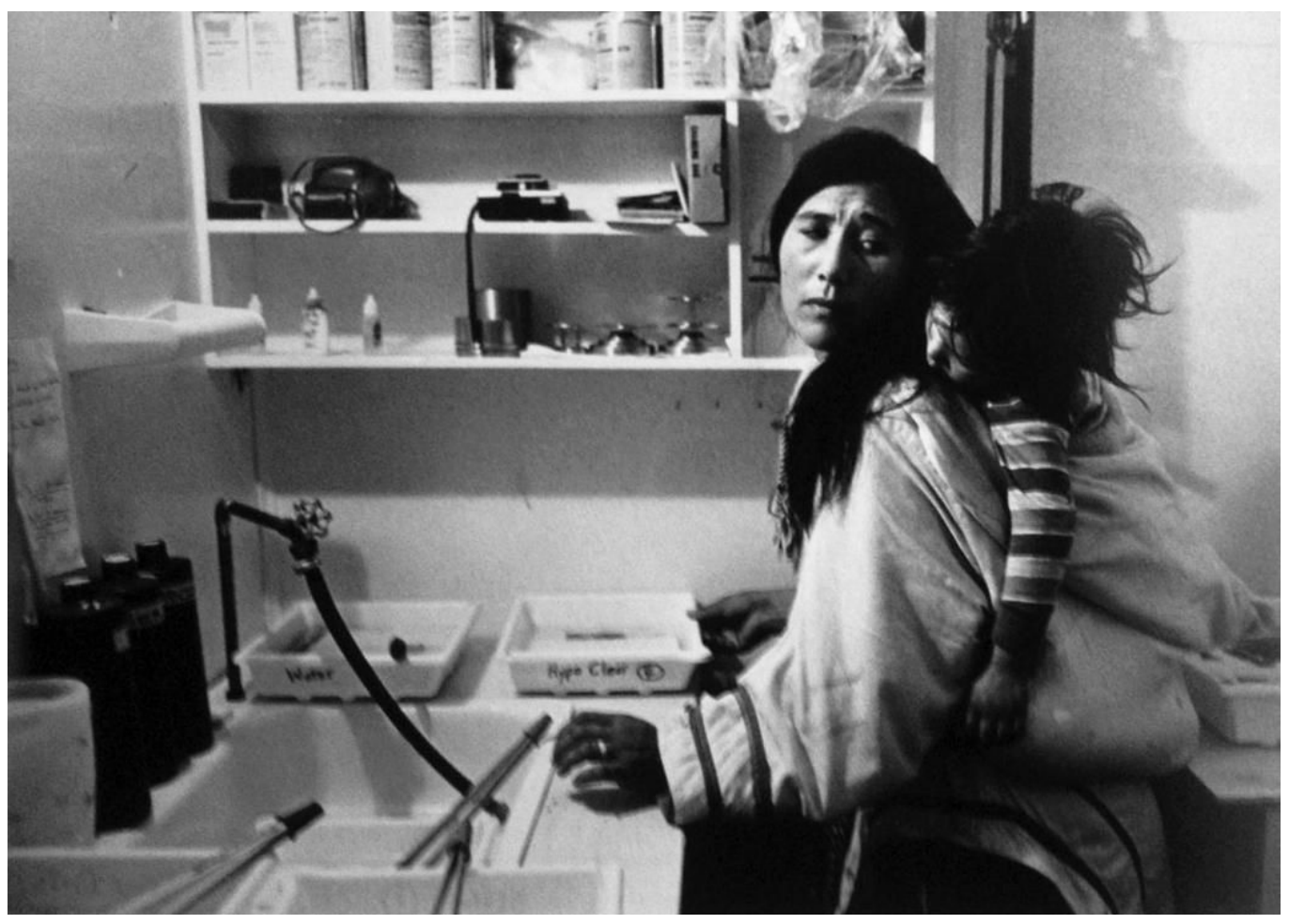

Figure 19. Nilauloq and Willie in Darkroom, 1973.

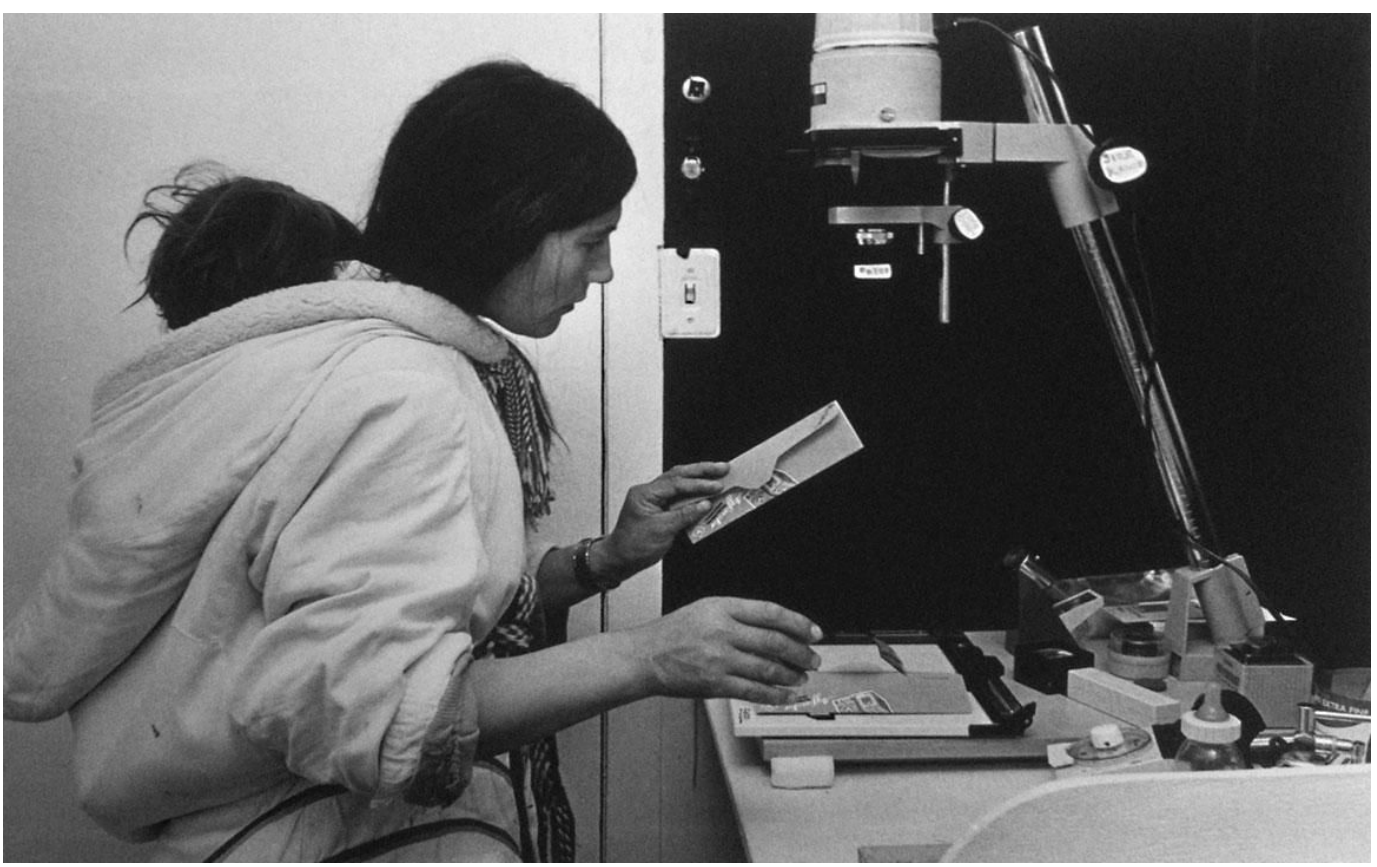

Figure 20. Nilauloq and Willie in Darkroom, 1973. 
for granted, such as plywood, or copper piping-were not easy to come by in Spence Bay. "Everything, every piece of wood, everything has to be brought there..."100

In a piece adapted from a report written by Harris, featured in Focus Magazine, Mary

Mallon describes the darkroom:

"The darkroom itself was $5 \times 7$ feet with a small bathroom sink (no taps) and a small collapsible table. By dint of hard work the final result was a light-proof room, with a sturdy work table and shelves running its entire length, a separate drying table, plenty of electrical outlets and a sink with cold running water and drainage. The craft shop is now equipped with a large water tank and an electric pressure pump for running water. At present, hot water is produced in an electric tea kettle. Water is a problem as it is delivered to the town by truck from a lake and therefore is very scarce. There was a delay in installing drainage for the sink so that for the first two and a half months the sink drained into a bucket which was then dumped outside."

This chapter will examine the darkroom project within a feminist pedagogical framework, and will analyze how this approach led to photography being utilized as a tool of empowerment. In 1972, many people in Spence Bay already had cameras and were engaging with photography. However, as Harris writes, "photography, like most of southern culture, was something that was passively consumed - they took the films to The Bay and a few months later got back the pictures. I thought it would be helpful for people to have the option of making their own photographs, not that they particularly needed photography, but that since they already had it, they should also have power over it, the power that comes from being able to do things

\footnotetext{
${ }^{100}$ Harris, interview, March 20, 2015.

${ }^{101}$ Mallon, "Photography at Spence Bay," 91.
} 


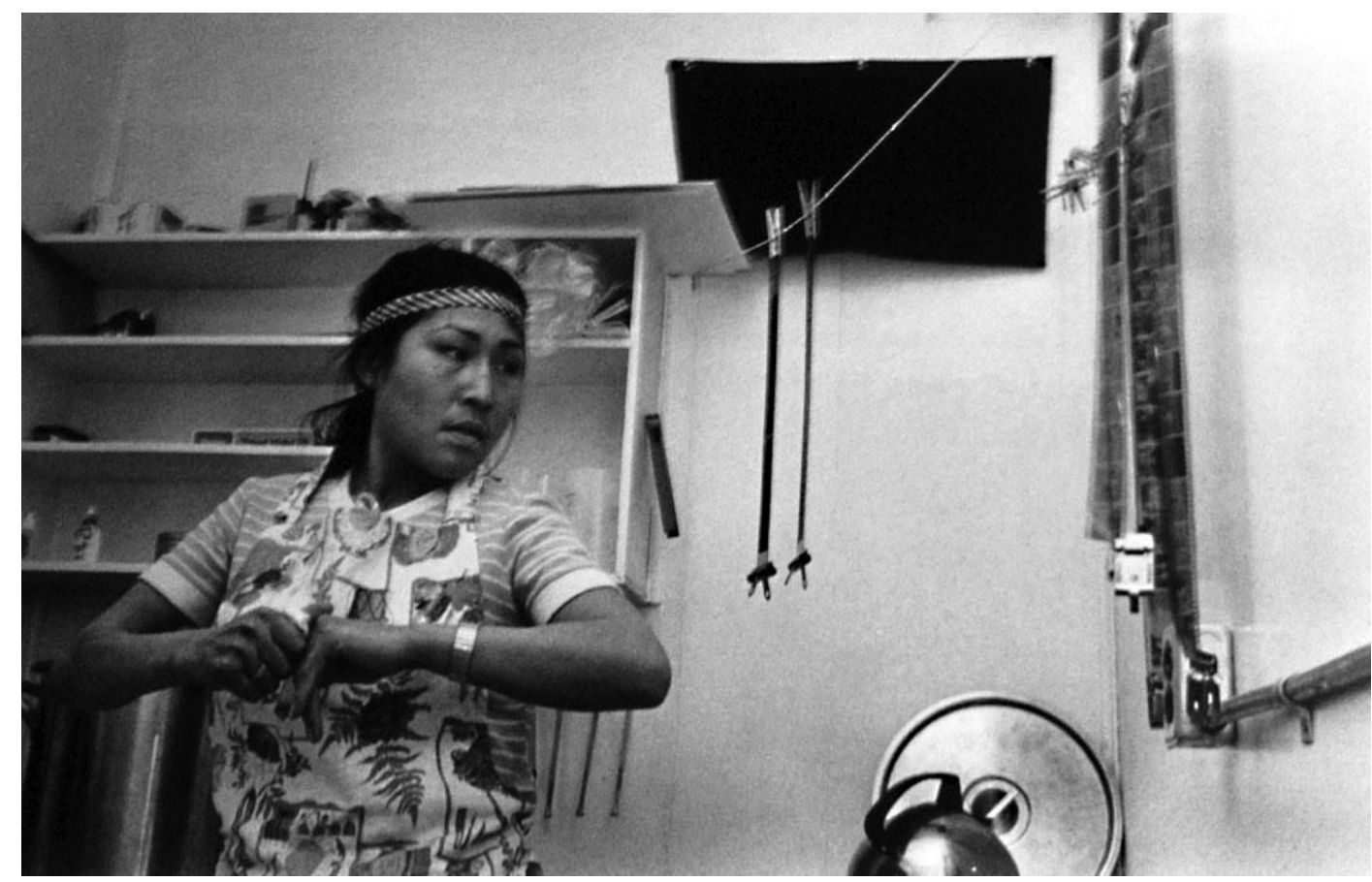

Figure 21. Selena Tucktoo in Darkroom, 1973.

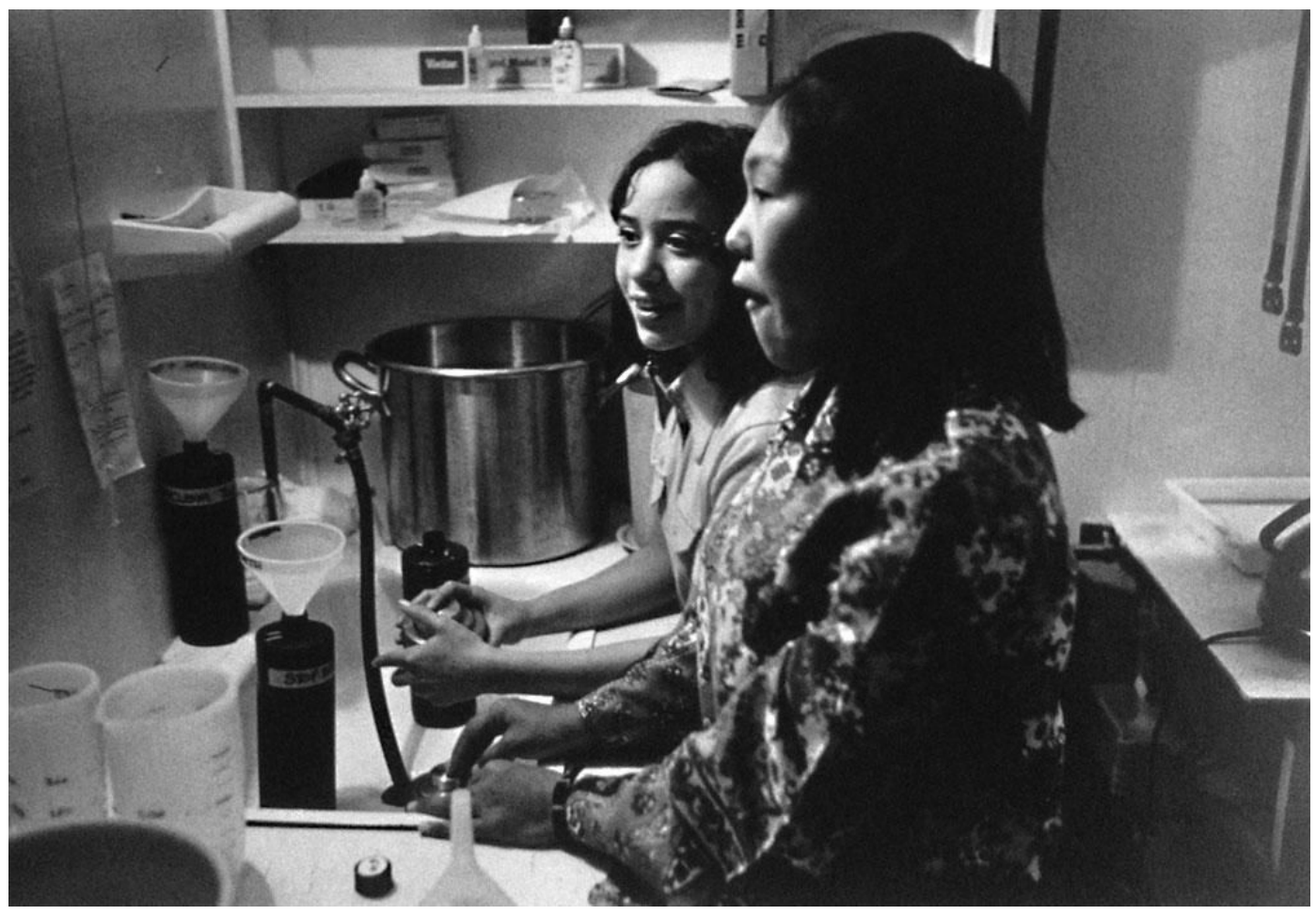

Figure 22. Loui and friend in darkroom, 1973. 
oneself. $^{102}$ It also creates a sense of autonomy; a skill that would continue on in those who participated, if they chose to do so. No longer would they need or submit to people from outside the community, to create photographic work for, or of them - but, of course, the choice was still there. "My intention," Harris writes, "was to provide people with the understanding of how the process worked and the skill of making their own photographs.... techniques by which the people of Spence Bay could tell their own story... The real story of the North, must be told by the Inuit themselves."

\section{“Cooking up Pictures:” Pedagogy \& Community Empowerment}

If it was important to include the community in her photography, then it was essential for Harris to involve them in the development of the darkroom project and in their own image making. In her writings, Harris acknowledged the importance of the community's response. She made a deliberate point of inquiring after their thoughts on the project, via correspondence with her friend McGrath, and letters directly received from community members. The significance Harris places on positive feedback to the darkroom project, prior to her second visit to Spence Bay, illustrates her consciousness toward the community's response to her presence, and to the idea of a darkroom. She writes:

\footnotetext{
${ }^{102}$ Harris, Another Way of Being, 58.

103 Ibid., 5.
} 
The practical background for this project is that I have already established a good relationship with people in Spence Bay. When I left, they were sorry to see me go and I have many letters encouraging me to come back. The photographs I sent up were warmly received. When I suggested the possibility of a community darkroom to Judy McGrath, she mentioned it to some of the people in the community and the response was enthusiastic. Numerous people are interested in learning photography, I have had several letters from individuals saying that they would like to learn to make pictures and one offering a room of her small house for the darkroom! ... One of the things that has been most encouraging is the very vocal interest in the darkroom possibility, and that sort of strongly spoken position seems to be an outgrowth of the women's project.

The darkroom was not a project imposed upon the community, but one that was welcomed and encouraged. If there had not been such a positive response, it is unlikely that Harris would have gone forward with it. Her approach was not to impose a specific teaching style with the workshops, but to allow the participants' needs to shape her educational technique. The goals for the darkroom project were clear: keep it simple, make good prints, and create a model of learning and teaching that encouraged people to work at their own pace, and in their own way. She explains: "I do not want to start with preconceptions of what would evolve from this darkroom. I think it is important just to take the material there, make the skills available to people, ${ }^{105}$ and let them take it in their own directions."

As a self-identified feminist, and someone immersed in the politics of second-wave feminism during this era, Harris was particularly conscious of and well versed in the critical aspects of the women's movement. Discussions regarding concepts of hierarchy, the politics of representation, and self-empowerment were prominent. Her awareness of these issues are echoed

\footnotetext{
${ }^{104}$ Harris, "Photographic Documentation Project," 8.

${ }^{105}$ Harris was open to teaching both men and women, but as she explains, "...it really was only acceptable for me to be in the darkroom with women, except for that one young couple, "cause he was with his wife." There were a couple men who did a few pictures, but the darkroom participants were predominantly women. Harris, interview, March 20, 2015.

${ }^{106}$ Harris, "Photographic Documentation Project," 5.
} 
in all aspects of the darkroom project, and how it was constructed. Between her first and second visit to Spence Bay, Harris initiated "The Women's Kit" while employed at the Ontario Institute for Studies in Education (OISE). It was an experimental multimedia kit, and OISE's "first explicitly feminist project."107 The kit was comprised of material about women—pamphlets, photographs, posters, audio recordings, slides, drawings - and distributed to educational institutions in Canada, as a teaching aid. ${ }^{108}$ The 1970s marked a time when OISE was hiring a number of feminist faculty members, and was described as "a pioneer in new approaches to education, especially women's education." ${ }^{109}$ Evidently, Harris's connection to OISE fostered a new way of thinking about education and alternative methods of teaching, especially for women. Her awareness of these ideas are echoed in the darkroom project. Both its structure and approach, was grounded in a feminist pedagogical framework, whether or not intentional. As stated in Feminist Pedagogy:

feminism encompasses ideas about the importance of women and women's experiences, histories of social movements seeking gender equality, a philosophy of humanism that works as a lens for understanding the entire human condition (not just that of women), and a critical analytical method that interrogates the relationships among gender, sex/uality, race, class, the environment, and power, often using misogyny as an organizing principle to explain inequalities and injustices in these realms. All of these understandings of feminism. and the multidisciplinary literatures that explicate them, inform feminist pedagogy.

\footnotetext{
${ }^{107}$ Julian Humphreys and Dawn Martin, eds., Inspiring Education: A Legacy of Learning 1907-2007 - Celebrating 100 Years of Studies in Education at the University of Toronto, accessed Aug 13, 2015, https://www.oise.utoronto.ca/oise/UserFiles/CENT\%20PUB_15_10_06.pdf (Toronto: OISE/UT, 2006 ), 62.

${ }^{108}$ Harris, interview, March 20, 2015.

${ }^{109}$ Humphreys and Martin, eds., Inspiring Education, 62, 63.

${ }^{110}$ Crabtree, et al., eds., Feminist Pedagogy, 1.
} 
Feminist pedagogy is a theory of teaching and learning grounded in feminist thought and politics. It is used as a framework to examine techniques used in the classroom, and a guide to analyze educational approaches, that have a specific outcome in mind. It is aligned with

a vision of the classroom as a liberatory environment in which we, teacher-student and student-teacher, act as subjects, not objects. Feminist pedagogy is engaged teaching/ learning - engaged with self in a continuing reflective process; engaged actively with the material being studied; engaged with others in a struggle to get beyond our sexism and racism and classism and homophobia and other destructive hatreds and to work together to enhance our knowledge; engaged with the community, with traditional organizations, and with movements for social change.

Harris taught in a non-hierarchical manner that did not perpetuate a power structure between teacher and student. The approach to the darkroom was an indication of the feminist ideas ingrained in Harris's modus operandi. It directly links her personal politics to the mandate and implementation of the darkroom workshop - a politics that encouraged respect regarding cultural differences, an awareness of power dynamics, and an interest in community engagement and empowerment.

Awareness and sensitivity are important when there are cultural and racial differences between people. Especially when one group has historically oppressed or exploited the other. As stated by bell hooks: "If the effort to respect and honor the social reality and experiences of groups in this society who are nonwhite is to be reflected in a pedagogical process, then as teachers-- ... we must acknowledge that our styles of teaching may need to change." ${ }^{112}$ Harris had to devise ways to teach the basic concepts of photography despite linguistic and cultural barriers between her and the darkroom participants. Some participants did not speak English, and

\footnotetext{
${ }^{111}$ Shrewsbury, "What is Feminist Pedagogy?" 166.

112 bell hooks, Teaching to Transgress: Education as the Practice of Freedom (New York: Routledge, 1994), 35.
} 

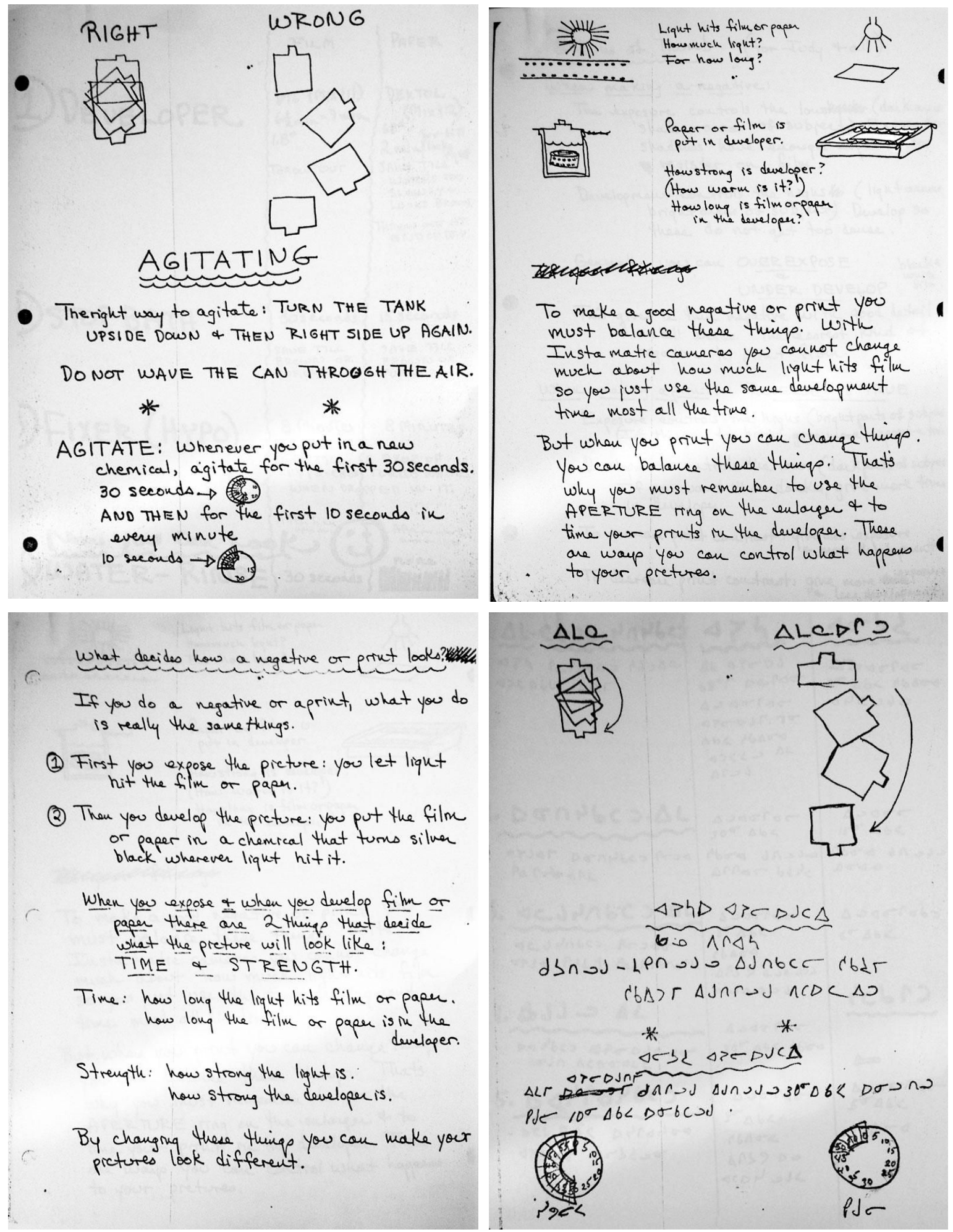

Figure 23. Darkroom Project instructional materials. 
one of them was a deaf mute. Things that Southerners take for granted, such as understanding the concepts of measurement and time, posed challenges in how to teach photography. ${ }^{113}$ As Harris explains: "Because I could not teach them in their own language, and because their language and background did not include many concepts and processes of the type involved in photography, I tried to translate everything into the simplest possible terms and to divide the whole process into bits they could handle. Most people learned very quickly." ${ }^{114}$ Examples of the instructional sheets devised by Harris can be seen in fig. 23, which show hand written documents, including illustrations, and the translation of instructions into Inuktitut. Her technique was practical: find ways to communicate, simply and clearly, in order for the participants to grasp the techniques needed to begin creating photographic work. Together they called it, "cooking up pictures."115 Harris approached the project with the knowledge that she herself had a lot to learn, and acknowledged that "As they were learning photography, I was learning how to teach photography. As I learned what areas would prove difficult, I could find new ways to make them easier. As I simplified the process, it got to the point where everything could be summed up on a few posted lists of steps, which were then translated into syllabics. By having a check list posted, people who were working by themselves for the first time had an aid to remembering what to do when. This made them feel more sure of themselves and of their ability to go it alone." ${ }^{116}$ Her methodology was to work with one person in the darkroom at a time, though on a few occasions, two; they were taught how to control the medium, and make their own choices. Harris states, "I

\footnotetext{
${ }^{113}$ Mallon, "Photography at Spence Bay," 92.

${ }^{114}$ Harris, "The Spence Bay Darkroom," 3.

${ }^{115}$ Harris, interview, March 20, 2015.

${ }^{116}$ Harris, "The Spence Bay Darkroom," 3.
} 
wanted the process of learning to make people feel more self-confident, able to do whatever they wanted to do." ${ }^{117}$ Harris explains further:

They would shoot a couple of rolls of film and then we would develop these. A day or so later we would print from these rolls. Learning was never theoretical; people were always working on material of their own in which they had a natural interest.... I would begin by explaining how photography works - in the simplest possible terms. Then, as we went through the development process, I tried to relate each stage to this explanation and to describe what each chemical was doing.... When there was something one could do to show how things worked (like turning on the light while a print was in the developer and watching it turn black) we did that. The second time we developed or printed, I asked people to pretend I wasn't there and to see what they could remember on their own, but with the assurance that if they were about to forget something or make a mistake, I would let them know. This wasn't a test, but rather letting them try it themselves. It worked well because it was fun. I was always there for help and there was never any stigma to needing help.... I tried never to pressure or chide anyone. No matter what was forgotten or what errors were made, it was always all right... It seemed to me that if they were going to undertake to learn this very new technology, they would have to do it in their own way, at their own pace, voluntarily and feeling good about it. ${ }^{118}$

When the roles of teacher and student are more distinct, and opposite- teacher teaches, students learn - an inherent power dynamic exists between the two. When every individual is viewed and treated as both, a relationship of equality is established, which reflects a non-hierarchical and non-oppressive model of learning, the feminist pedagogical approach. ${ }^{119}$ The darkroom workshop was not a traditional classroom by any means, but rather a group of people who came together to both teach and learn in their own ways, in an environment that treated everyone as both teacher

\footnotetext{
${ }^{117}$ Ibid., 2.

118 Ibid., 2-4.

${ }^{119}$ Crabtree, et al., eds., Feminist Pedagogy, 5.
} 
and student. Once they learned the process, they went on to teach each other, and one of the women, Selena Tucktoo went on to teach photography at a new school in the community. ${ }^{120}$

\section{The Photographer \& the Photographed: Voice, Power \& Representation}

Harris recognized the importance of helping the Inuit create their own photographic work, because doing so would contribute to a shift in power. Creating photographic work was a way to control one's own representation, or the representation of one's community. Harris explains: "Doing something yourself is a kind of power.... Since there is already a sweeping cultural invasion of the North by the rest of the world, there is some urgency that the Inuit should have as much control of his culture as possible. Photography is one way." ${ }^{121}$ An analysis can be applied to the visual culture surrounding Indigenous people. Historically, they have been depicted visually in preconceived notions of what Indigenous culture means. It is not their voice or perspective being heard or shown, but that of the objectifier, the outsider. As Harris writes: "they [the Inuit] are also people who are being exposed to a barrage of photographic images for the first time... When there are native people in the community who can produce photographs, they would have the option of recording themselves and doing their own interpretation, rather than always being shown to the outside world by outsiders." ${ }^{122}$ When you place the control in the hands of the community being represented, it is their perspective that is now being seen. It is their voice and their lives, and not a projected construction.

\footnotetext{
${ }^{120}$ Harris, interview, March 20, 2015.

${ }^{121}$ Dault, "Photography Helps Inuit Control Changing Culture," 1976.

${ }^{122}$ Harris, "Photographic Documentation Project," 6.
} 


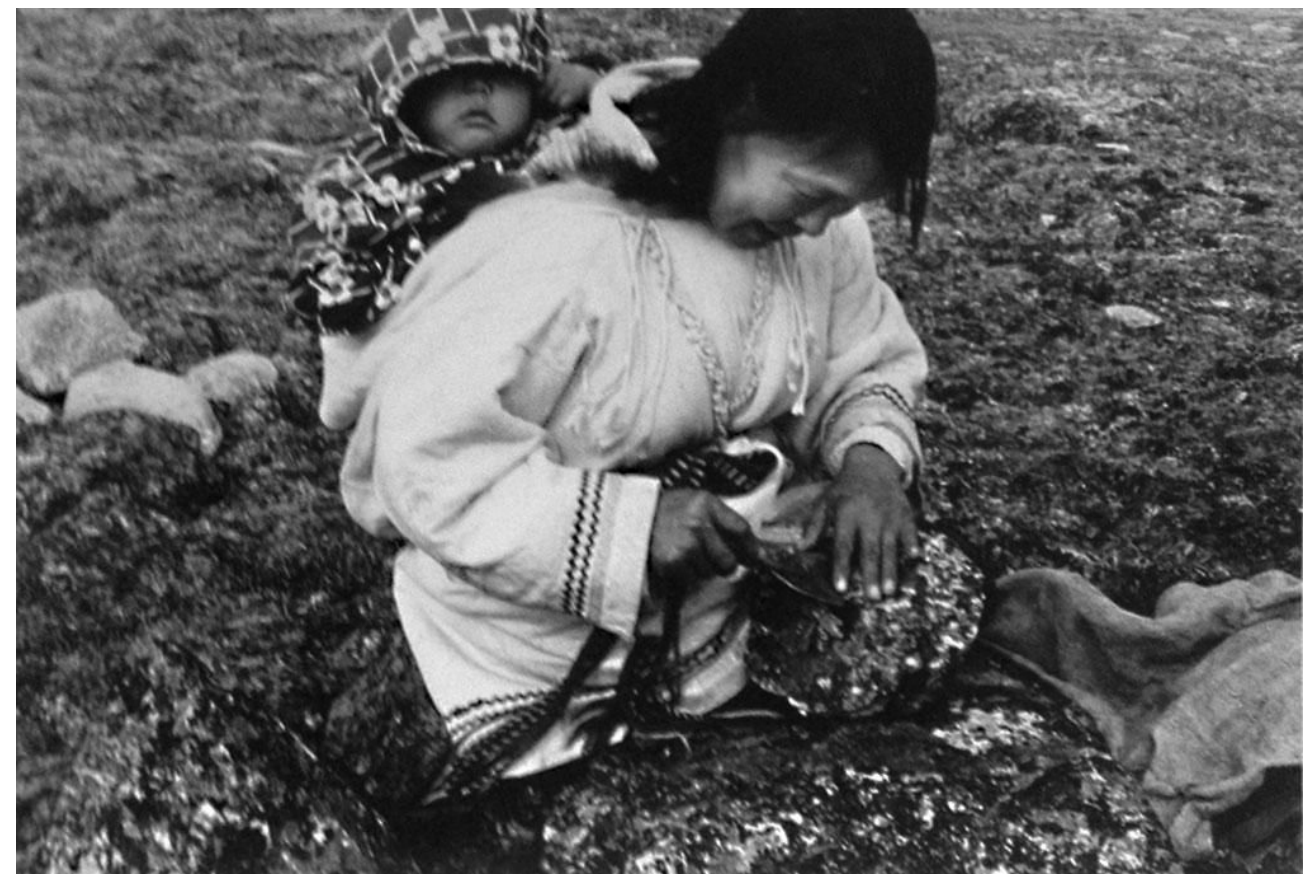

Figure 24. Theresa Quaqjuaq, Untitled, 1973/74.

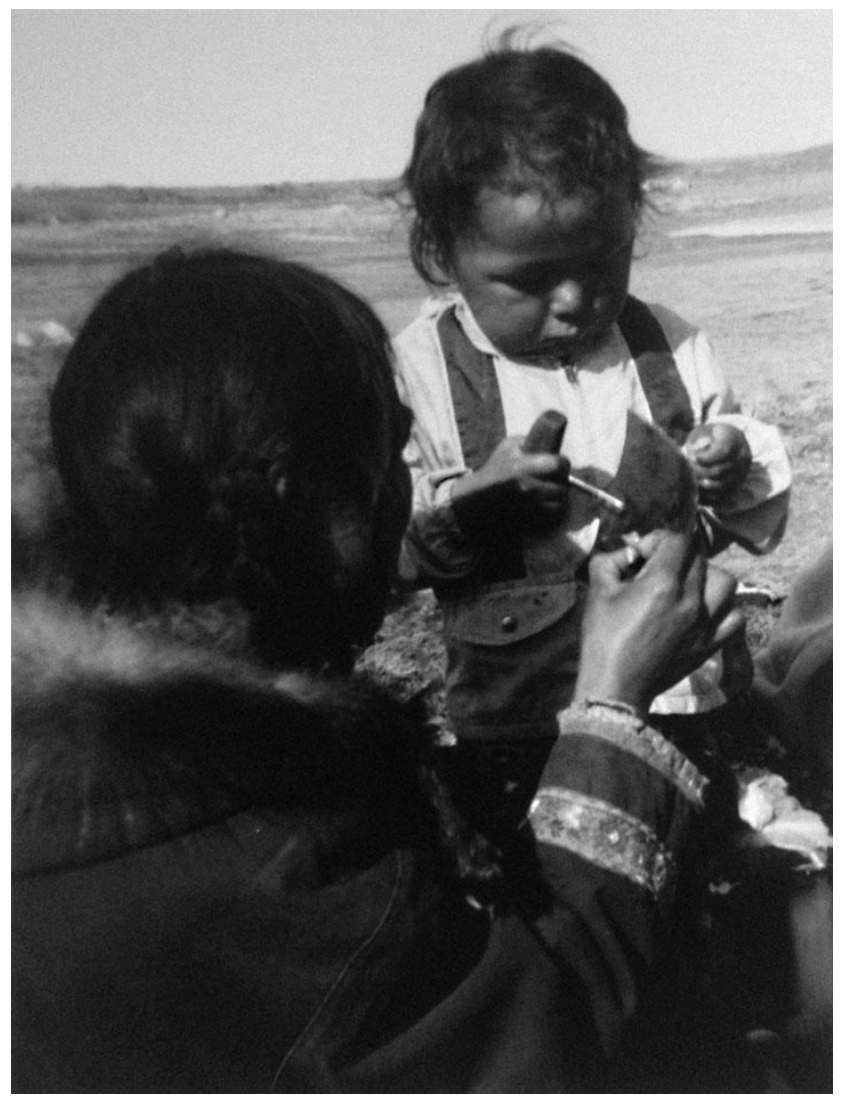

Figure 25. Unknown Photographer, Untitled, 1973/74. 
The camera is a powerful tool—sometimes referred to as a kind of weapon — and historically it has been utilized by white colonizers to photograph Indigenous communities. ${ }^{123}$ Non-Indigenous people have created the vast majority of images depicting Indigenous life. The viewer's understanding is therefore seen from the perspective of an outsider, and not from someone who is representative of the represented community. The power held by the photographer, in controlling how things are represented, must be acknowledged. One must ask, from what vantage point, what context is the photograph created in? As stated by Payne: "photography is by no means a neutral and objective trace of the world. Instead, it mediates the visible through subjective selection of subject matter, vantage point, and framing; alterations in depth, colour and tone; the extraction of one fraction of time from a temporal continuum; the exclusion of other sensory information and, usually, binocular vision; and recontextualization through placement, accompanying language, and reception." ${ }^{124}$ In the context of Indigenous representation, this statement warrants a closer analysis.

Control over photographic representation can aid in individual and/or community empowerment, accomplished by "analysing ideas about the causes of powerlessness, recognizing systemic oppressive forces, and acting both individually and collectively to change the conditions of our lives. ${ }^{125}$ Harris recognizes the power embedded in photography, it can be both oppressive and empowering. It is this empowering aspect that was utilized through the darkroom, as it was an active and implemented model that served to accomplish the goal of community empowerment. She writes: "there is the possibility of community documentation, done by the people in the community, ... it should be a process that would strengthen the community's sense

\footnotetext{
${ }^{123}$ Payne and Kunard, eds, The Cultural Work of Photography in Canada, 70.

${ }^{124}$ Payne, "Through a Canadian Lens," 425.

${ }^{125}$ Paechter, Educating the Other, 67.
} 


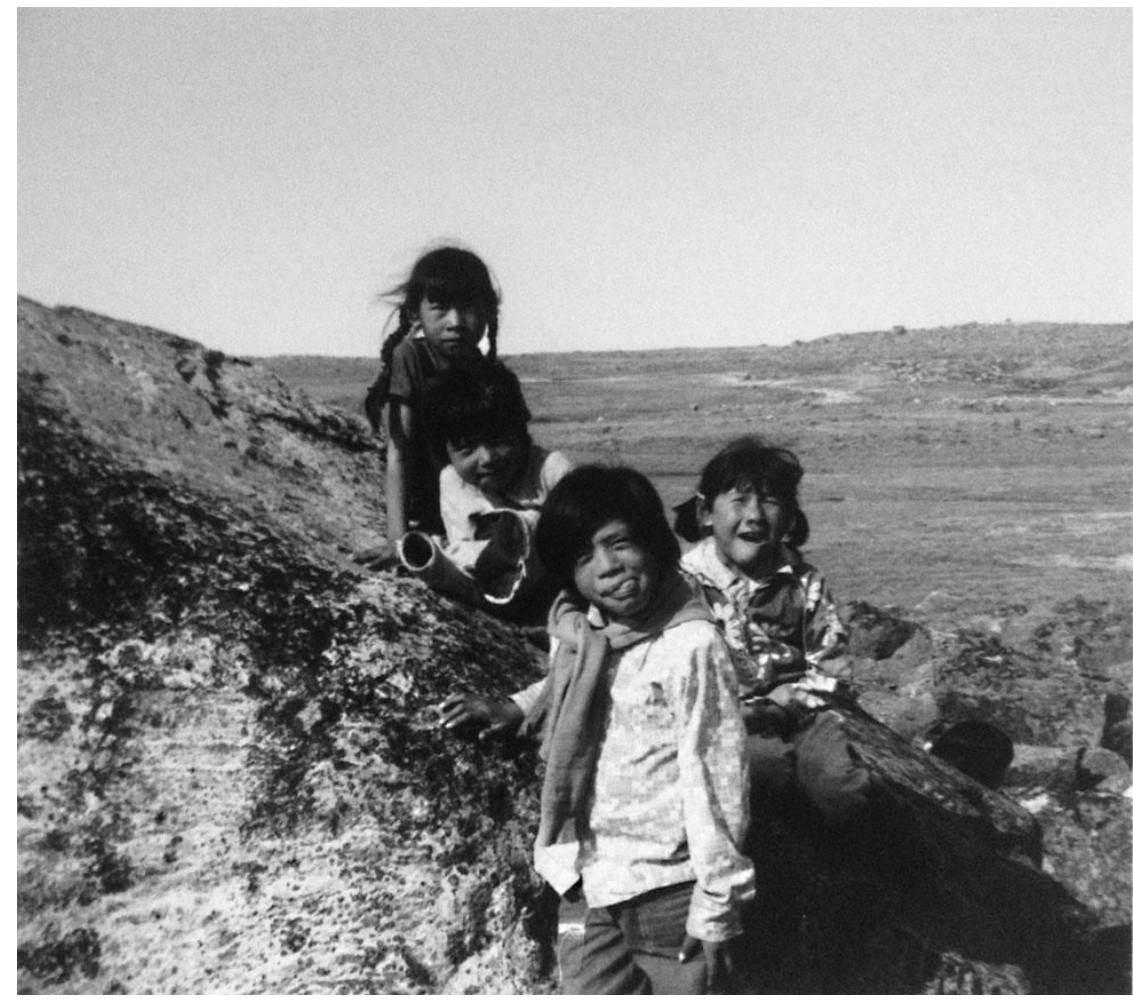

Figure 26. Selena Tucktoo, Untitled, 1973/74.

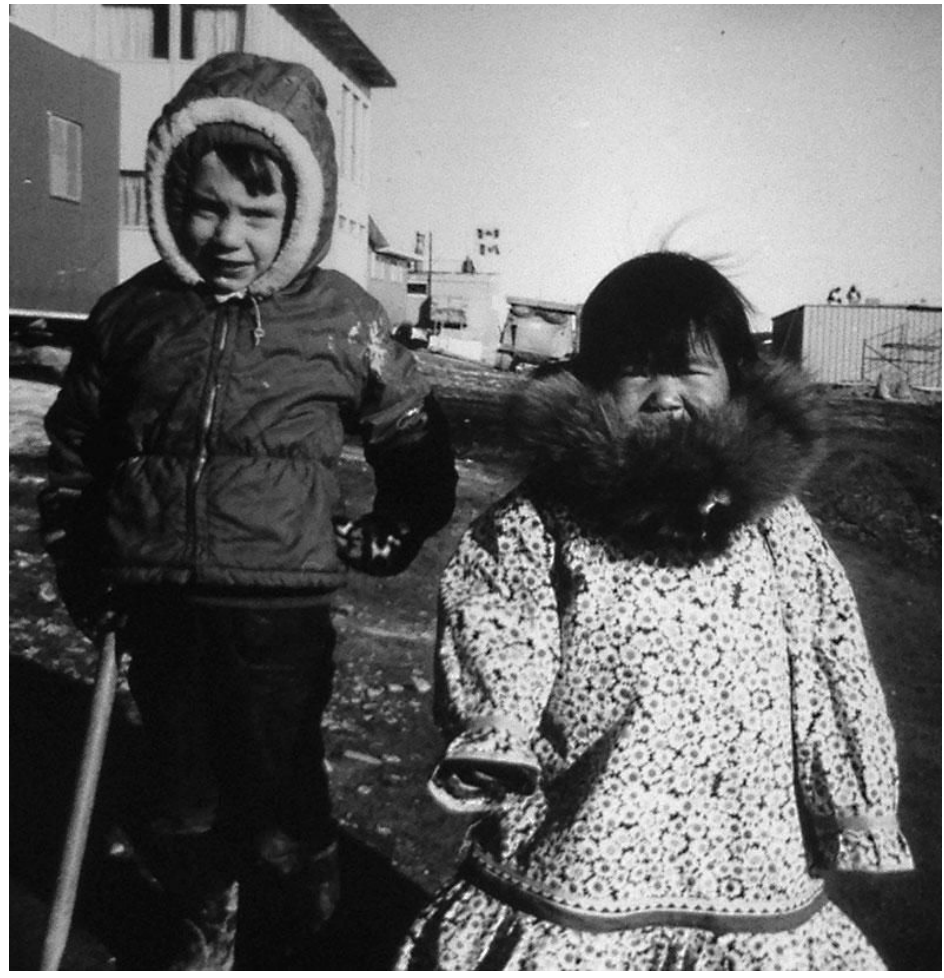

Figure 27. Teresa Totalik, Untitled, 1973/74. 
of self, what they have, who they are. This is a very important process in a place that is in itself new and alien to most of the inhabitants and that is constantly bombarded with an ever escalating amount of information and pressure from the alien Southern culture." ${ }^{126}$ The darkroom served as an initiative that supported the philosophies of individual choice and control over visual representation. The darkroom was a tangible project that the community members could utilize; actively involved in their lives, with observable impact. That lived experience reverberates through the photography they created (fig. 24, 25, 26, 27), through the context of where they exist, into those who view it, and into Indigenous discourse. Their visual perspective is now an official part of the collective story, created by the numerous photographers that made representations of Indigenous life.

The notion of choice in how one is represented gives voice to those who have been historically silenced. Indigenous representation in photography has predominantly been archetypal - nameless, and thus voiceless. In the political and social context of the 1960s and early 1970s, within a discourse of challenging oppressive and exploitative structures, having one's voice heard was significant. Political activist movements during this time, such as the women's movement, the anti-Vietnam war movement, the civil rights movement, etc., embraced a climate in which the voices of the historically silenced are now provided a space to speak. Photography is a way in which one can speak visually, and in a sense be heard. As discussed in the context of feminist pedagogy, some voices are given more legitimacy, and "it is therefore essential that those who would wish to develop an empowering pedagogy give space to those voices that would otherwise remain silenced." ${ }^{127}$

\footnotetext{
${ }^{126}$ Harris, "Photographic Documentation Project," 6-7.

${ }^{127}$ Paechter, Educating the Other, 67.
} 
Selena Tucktoo (fig. 21), one of the darkroom participants, was asked by Harris to describe her experiences with the workshop, and her feelings on producing photographic work (fig. 26). She states:

I took all kinds of pictures to show what people did this summer. It's always fun to see what we did before. And maybe show people in other places, show them what we did with flowers and lichens, show them how they can be used. When I was taking those pictures I never thought of showing them to people in other towns; I just thought to keep them to myself. I like to keep them to myself but I like to show people, too. I like to tell them what we did... I like the women in the shop to see what pictures I did, give them free pictures.

It is apparent from how she speaks about the photography workshop that she found pleasure and pride in the work she produced, and in showing it to others. It was work produced from observing and documenting her own life, an acknowledgment of her perspective, and an act of self-empowerment.

The following excerpt, from Harris's written documents, illustrates how photography was used as a documentary tool. It succeeded in helping the Inuit create their own photographic work, by documenting the dye workshop they participated in:

We had been promised an additional $\$ 500$ if the darkroom group supplied the Department of Economic Development with a photographic documentation of Judy McGrath's summer dye workshop. I had had reservations about the attempt to combine learning photography and aiming at a product. However, beginning photo work with an assignment proved to be a very good idea. First of all, both the dye workshop and the craft project were funded by Manpower, and of the many women who were salaried to collect dye-plants, or to sew, a small number wanted also to learn photography. These women could thus be paid to do this documentation and hence were willing to concentrate on pictures of these activities and to make the necessary prints. If they had not been salaried I think the situation would have been quite different. Secondly, it just

\footnotetext{
${ }^{128}$ Pamela Harris, as told to by Selena Tucktoo, "Learning to Make Pictures" [1973], Series 2, file 2-12, Pamela Harris Papers, E.P. Taylor Research Library and Archives, Art Gallery of Ontario, Toronto, p. 2.
} 
seems to work well to have a common goal. The dye workshop was so terrific anyway - the camaraderie, the spirit, the hardwork and the enjoyment of that work, the link to traditional activities - this was an activity that everyone enjoyed and was proud of and so of course it was lots of fun to make pictures of it. Thirdly, these women who did the documentation were not simply photographing. During the summer they also walked out everyday with the other women, carrying food, tea kettles, kids, bags - their Instamatic X35's and a couple of rolls of film tucked in a pocket or at the bottom of a haversack with the bannock and tea bags. They scraped lichen, picked flowers, changed diapers, made tea - and took pictures. They were part of the process they photographed; they were themselves photographed by each other; there was no division between photographer and subject.

Since the dye workshop and the darkroom existed in the same physical space, it made sense that they would make use of each other, and that the projects would collaborate in some way. Some of the darkroom participants documented the dye workshop excursions, thus producing photographic work made by their own community members. In so doing, it allowed both groups to see the significance of the dye workshop and share its importance to a wider audience. In 1974, their photographic work was shown in an exhibition at the Arctic Women's Craft Conference, held at the Toronto Dominion Centre in Toronto (fig. 28, 29).

Another anecdote illustrates the pride and accomplishment felt by the darkroom participants: there was a visit from the Commissioner's (of the NWT) publisher, who "came from Yellowknife with a photographer to 'do' the dye workshop for the Commissioner's book. The women in the workshop decided among themselves that this was not something they wanted, and one of their major reasons for expressing their feelings in this way was that they felt (to quote) 'We have our own photographers now."' ${ }^{130}$ Selena Tucktoo describes the same incident:

\footnotetext{
${ }^{129}$ Harris, "The Spence Bay Darkroom," 5-6.

${ }^{130}$ Ibid., 7.
} 


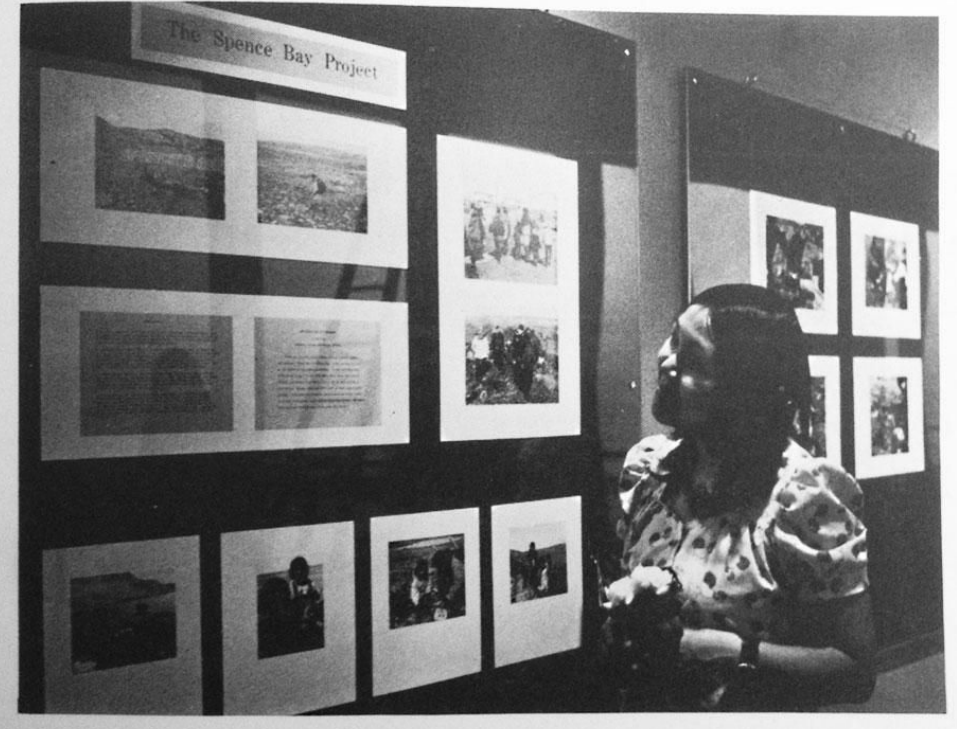

The Spence Bay Ptoto Show at the Arctic Women's Workshop.

Figure 28. The Spence Bay Photo Show at the Arctic Women's Workshop, in Arctic Women's Workshop, 1974.

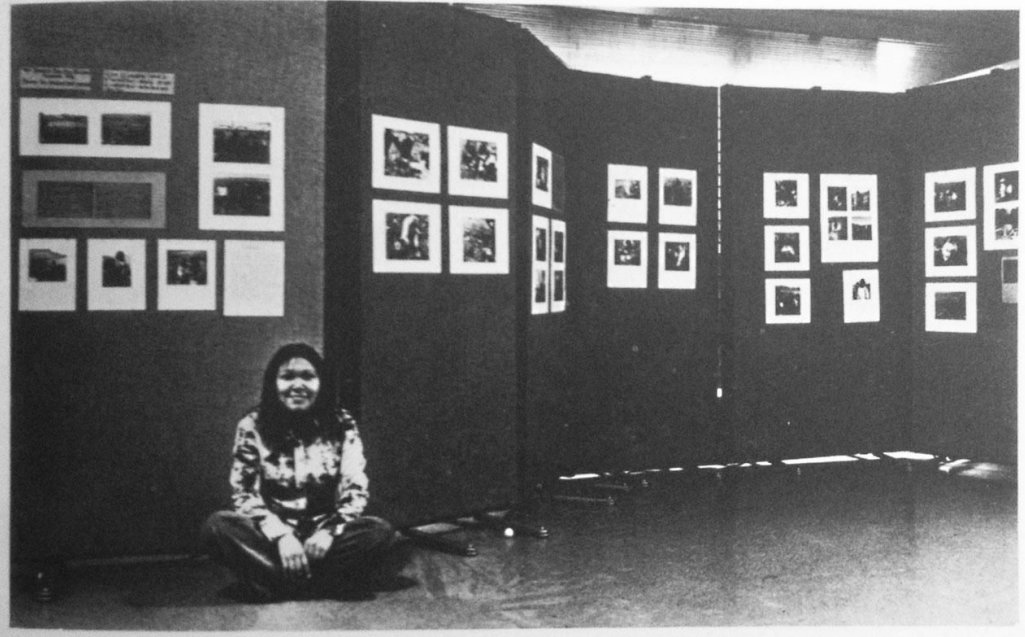

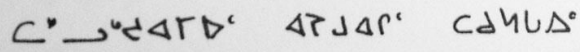

$$
\begin{aligned}
& \ln L n \rightarrow f^{\infty} \quad 4^{a} a \Delta
\end{aligned}
$$

Figure 29. The Spence Bay Photo Show at the Arctic Women's Workshop, in Arctic Women's Workshop, $1974 .{ }^{131}$

${ }^{131}$ The publication Arctic Women's Workshop included both English and Inuktitut. 
That time when that man came from Yellowknife- that was the first time I heard of not letting anyone take pictures of the ladies.... they said they didn't want him to take pictures of them cause they already got somebody to take pictures of them, they got their own photographer. I felt proud. That's the reason why they all said no... The people who come in, I don't even know who they are some time. Sometimes I get really scared. (Asked why she thought the women preferred to be photographed by her.) Because they know me; they didn't get nervous.

The proclamation of "We have our own photographers now" exemplifies the autonomy felt by the Inuit women. They now had a position to assert themselves, and deny an outsider from fulfilling a job that they themselves could do. That is empowerment, and that is the success of the darkroom. Harris writes: "the pictures they produced are pictures Southerners could never take. These are pictures taken by insiders_-people who understand what they are photographing from the inside and who are making pictures of their friends and relatives." ${ }^{, 13}$ The fact that the photographers were women, and that they were documenting women's work (the dye workshop), is incredibly relevant in this era of second-wave feminism. The Inuit women were recognized as active participants in the telling of their own stories, and created photographic work that applies to and documents their own lived experiences. The images they produced are not overtly distinct from a visual analysis. Their significance lies in the social context of their creation, having control over their own visual representation, and deciding what the act of photographing symbolically represents to the members of their community.

\footnotetext{
${ }^{132}$ Harris, as told to by Selena Tucktoo, "Learning to Make Pictures," 2.

${ }^{133}$ Harris, "The Spence Bay Darkroom," 6.
} 


\section{CONCLUSION}

The social and political consciousness of the late 1960s and early 1970s had a significant influence on the implementation of the Spence Bay project, and are directly linked to Harris's approach and methodology. Due to her position as an outsider, Harris carefully examined her approach to photographic work, and the educational aspects of teaching photography. Her involvement with the women's movement was especially influential and, when coupled with her rich background in education, resulted in an educational philosophy that stressed a nonhierarchical and shared exchanges of teaching and learning. The politics of representation, knowledge formation, objectification, and empowerment, also resonate with Harris’s methodology.

The Spence Bay photographs are a significant contribution to the already existing Aboriginal visual history, created decades prior, by other skilled photographers. It is a continuation of the practice of photographing in the Canadian North. That being said, Harris recognized that a group of photographs can never "represent the totality of the experiences," 134 which is why she chose to couple the photographs with text sourced from the photographic subjects themselves. What cannot be shown, must be told. This inclusion created a body of work that highlights the subject first, and the photographer second; supporting Harris's view of photography as a window onto the world, rather than a mirror turned on herself. She states: “A good photograph is an epiphany; it throws everything else into focus. Even so, it is only a touch of one moment, and the documentary photographer ought to be incredibly humble in the face of the larger reality which he has left behind." 135

\footnotetext{
${ }^{134}$ Marjaleena Repo, "Photography and the Powerless," This Magazine is About Schools 4, no. 1 (Winter 1970$): 134$.

${ }^{135}$ Pamela Harris, “And a Reply:," This Magazine is About Schools 4, no. 1 (Winter 1970): 141.
} 
Harris's photographic work does not present the Inuit of Spence Bay as an idealized or romanticized people, projected through a condescending empathy. Similarly, it does not subscribe to the notion of a race of people vanishing into history. The cultural transition Harris witnessed was not viewed as something that was going to inevitably erase their traditional way of life. Harris created images of a community that has relevance in contemporary society — present, here and now, not historical figures of the past, to be pitied, belittled, or put on display as objects. Southern viewers are confronted by both familiar and unfamiliar visual elements in Harris's photographs, disrupting the preconceived image that society has been exposed to by previous image makers. It is a community not disappearing, but transforming, and coexisting in a Northern and Southern cultural dichotomy. Harris depicts a more complex view of Inuit life, dispelling stereotypes, and therefore widening the representation. It is also, in some ways, a simplified representation that celebrates their ordinariness, ${ }^{136}$ as unspectacular people, in the most humbled and dignified way. It is through this lens that their humanity is fully present. That is the legacy of this project.

The darkroom project was a culmination of Harris's feminist ideals and of her exposure to, and involvement with, experimental education discourse. Its implementation was collectively accomplished, by Harris and the Inuit participants, and utilized photography as a tool of empowerment; a practical project of utilitarian value. The darkroom participants used photography to directly contribute to the visual history of their own lives, a radical departure from the majority of photographs of Indigenous peoples throughout history. In these photographs, the Inuit exist as both subject and creator, which diminishes the possibility of "otherness;" they exist as one and the same. Participation in the process of photography, and

${ }^{136}$ As Harris stated herself. Harris, interview, March 20, 2015. 
having a sense of control over it, granted a sense of autonomy to the women of Spence Bay, and aided in diminishing any presumed dependence on non-Indigenous society.

Harris's unique perspective allowed for an alternative approach in creating a photographic documentation of Inuit culture. The result is a body of work distinct in its representation. One of dignity, meant to enrich and strengthen all those involved in its production. The Spence Bay project represents a shift in Indigenous visual discourse. This is photography not just of community, but for and importantly from the community. 


\section{APPENDIX A}

Pamela Harris Interview Questions \#1 - March 20, 2015, Toronto, ON.

-What was happening in the late 1960s or early 1970s, for you, that you feel led toward the Spence Bay photography project? What were you reading, doing, or seeing that may have influenced you to embark on this project?

-What was the political and social climate like for you then? Was there anything happening politically that was inspiring you?

- Could you elaborate on how your being a feminist influenced your approach to this project? In what capacity do you think it shaped how you photographed, as well as how you taught the darkroom workshops?

- Do you feel like Another Way of Being received a fair amount of press or attention? If not, why do you think that might have been? Do you think that you being a woman had anything to do with that? Do you think if a man had carried out a similar project, in the 1970s, it would have received the same amount of attention?

- Is there anything you would change about the selection (or anything else) in the book Another Way of Being? Would you include more or different images? More or less writing? How do you feel about its size?

- Is there anything you would do differently now, with either the darkroom project or your own photography work in Spence Bay? Are there things you wished you had photographed but didn't? Is there anything you would change in how you taught or ran the darkroom workshops?

- Did you leave Spence Bay feeling satisfied with what you had accomplished there? Was there ever a desire to go back to complete something that felt unfinished?

- Are you still in touch with any of the individuals you met in Spence Bay?

- How did you and Judy meet, before she went up to Spence Bay?

-What most ties you to these two projects (Spence Bay and Faces of Feminism)? What about you (your perspective/approach) do you see manifested most in them?

- I saw that you attended the Native Indian and Inuit Photography Conference in Hamilton in 1985. What issues were being discussed? Did you speak at it? Was your book showcased or

- Do you consider yourself a documentary photographer? If yes, what does documentary photography mean to you? 
- Any final or general thoughts on the project, 40 years later, that you'd like to mention?

- Do you still photograph? Any ideas for future projects? 


\section{APPENDIX B}

Pamela Harris Interview Questions \#2 - May 14, 2015, Art Gallery of Ontario, Toronto, ON.

- In your writing, you often mention the tension that existed between Northern and Southern ways of being. Did you aim to capture this dichotomy in your photography, and if yes, do you think you were successful in doing so?

- Do you feel that any of the photographs represent both Northern and Southern ways, or do the majority of the images just show one or the other? Or is it that the photographs as a group are meant to convey this?

- Many of your images are portraits of people, seemingly posed. How often did you instruct people to gather or sit together in order for their photograph to be taken? Did you ever direct the sitters? To smile, embrace, lean in to each other, look away, etc.?

- The majority of your photographs have a very happy and lighthearted feel to them - people are smiling, playing, enjoying their task, etc. Do you feel you shied away from photographing moments that were less pleasant, that perhaps showed some of the hardships or struggles of the Spence Bay community? Or did you not witness much of this while you were there?

- What are some of the lasting impressions that Spence Bay left on you? Do you think these impressions are conveyed in your photographic work? Do you think that the viewer now can accurately sense what it is you were trying to convey about the community then? And what would you describe those things to be?

- From your previous work as well as from your writing, it is apparent that you are particularly interested in the lives of women. Do you think you paid closer attention to women in your photographic work in Spence Bay? What aspects of their lives did you find most interesting, challenging, fascinating, etc., and in which images do you feel this was captured? 


\section{APPENDIX C}

Excerpt from “A Conversation” in Another Way of Being, 11-12.

Pam: What do you think of doing with the rest of your life? Like, do you think of what you're going to be doing in ten years? Have any plans?

Jude: I don't know. Well, my father kept telling me I should be like some other young peoples. Cause today the young peoples are change. Most of them are speaking in English, and most of them are acting like white peoples, like English. And most of them don't want to go out hunting; they just want to work, like, get a job and stay at it... But I like hunting better, cause... I just don't know why.

Pam: So your father isn't pressing you to stay in the traditional ways? He would like you to change?

Jude: Well... You know, I been going out to school; and each spring I have to get home; every spring I have to go back home. And around August I have to leave to Inuvik and come back June, around end of June. And like, those days, other young people were just like any other Eskimo, because they stay home all the winter and summer. But I was one of the kids who go out to school like white peoples, as if I was going to be a white person. But I don't really like it that way. Everything change around. I rather be an Eskimo, a real Eskimo, who never speak English. I kept telling my friends I should never go to school... Because, it's going harder every year for me. Well, like, you know, if I had parents who know about English, if they know about English as well as Eskimo, it would be a lot easier, I think. But with your parents just plain Eskimo who never know about the life of the English, it's hard... I understand my parents, but they don't understand me sometimes, how I act, and sometime when I say something that I mustn't say. You know. I don't have the same brains, I guess. Different way of thinking and different way of acting....

Pam: Maybe you could try and tell me a little more about what you feel is the difference between being a real Eskimo and being an English Eskimo....

Jude: The things change... Today... it's as if they're hungry for money... Like, another person gets, maybe, a new kicker or a skidoo or a canoe-looks as if another Eskimo is jealous... Looks as if the money is their Dad now. Cause they're only earning their living by money now, most of them anyways. But years ago they used to live by only meat and fish. Or maybe caribou, caribou meat and seal meat, maybe polar bear. And they used to never think about money, cause they got enough food. Maybe they care for the money cause they want to buy the stuff that they see from The Bay; like, in the store, they look at something, "That's good," he wants to buy it now. That's why they care about so much money... It's really funny because, you know, few years ago, most of the Spence Bay Eskimos were living in the igloos, and they didn't know anything about the white peoples 
and how they live. They know little bit of it, but not that much. And now today they're all dressed up like white peoples and living in a house, and they're trying to be as clean as they can. And, I just don't know why I say that. But, it's strange. If I was an old timer, I would never change my life... 


\section{BIBLIOGRAPHY}

Bernardin, Susan, Melody Graulich, Lisa MacFarlane, and Nicole Tonkovich. Trading Gazes: Euro-American Photographers and Native North Americans, 1880-1940. New Brunswick, NJ: Rutgers, 2003.

Chang, Zulay Jau Ting. "A Full Catalogue and Analysis of Photographs and Photogravures by Robert J. Flaherty at the Art Gallery of Ontario.” MA Thesis, Ryerson University, 2010.

Close, Susan. Framing Identity: Social Practices of Photography in Canada, 1880-1920.

Winnipeg: Arbeiter Ring, 2007.

Cole, Barbi. “Unique Crafts From Our Arctic.” Toronto Sun (June 27, 1974): 27.

Condon, Richard G. "The History and Development of Arctic Photography." Arctic Anthropolgy 26, no. 1 (1989): 46-87.

Crabtree, Robbin D., David Alan Sapp, and Adela C. Licona, eds. Feminist Pedagogy: Looking Back To Look Forward. Baltimore: John Hopkins University Press, 2009.

Dault, Gary Michael. "Photography Helps Inuit Control Changing Culture.” Toronto Star, July 2, 1976.

Davidov, Judith Fryer. Women's Camera Work: Self/Body/Other in American Visual Culture. Durham, NC: Duke University Press, 1998.

Davis, Robert. "Editorial.” This Magazine is About Schools 1, no. 1 (April 1966): 1-4.

Department of Indian and Northern Affairs. Arctic Women's Workshop. Ottawa: Department of Indian and Northern Affairs, 1974.

Eber, Dorothy Harley. "Peter Pitseolak and the Photographic Template." In Imaging the Arctic. Edited by J.C.H. King and Henrietta Lidchi, 53-59. Seattle: University of Washington Press, 1998.

Edwards, Elizabeth. Raw Histories: Photographs, Anthropology and Museums. Oxford: Berg, 2006.

Flaherty, Robert Joseph. Robert Flaherty, Photographer/Filmmaker: The Inuit, 1910-1922: An Exhibition. Vancouver: The Vancouver Art Gallery, 1979.

Francis, Daniel. The Imaginary Indian: The Image of the Indian in Canadian Culture. Vancouver: Arsenal Pulp Press, 2011. 
Geller, Peter. Northern Exposures: Photographing and Filming the Canadian North, 1920-45. Vancouver: University of British Columbia Press, 2004.

Grace, Sherrill E. Canada and the Idea of the North. Montreal and Kingston: McGill-Queen's University Press 2001.

Harrington, Richard. Richard Harrington, Canadian Photographer. Edmonds, WA: Alaska Northwest, 1998.

—. The Inuit: Life As It Was. Edmonton: Hurtig Publishers, 1981.

Harris, Pamela. “And a Reply:” This Magazine is About Schools 4, no. 1 (Winter 1970): 137-141.

—. Another Way of Being: Photographs of Spence Bay N.W.T. Toronto: Impressions, 1976.

—. "Arctic Women.” Branching Out (July-Aug 1976): 20-27.

—. Faces of Feminism: Portraits of Women Across Canada. Toronto: Second Story Press, 1992.

—. Interview by author. Audio Recording. Toronto, March 20, 2015

—. Interview by author. Audio Recording. Art Gallery of Ontario, Toronto, May 14, 2015.

—. "Mary Edetoak." This Magazine 8, no. 3 (Aug-Sept 1974): 18-19.

—. "On the Land: Photos and Text by Pamela Harris." This Magazine 10, no. 5 (Nov-Dec 1976): 24-25.

—, Papers. Spence Bay Collection. E.P. Taylor Research Library and Archives, Art Gallery of Ontario, Toronto.

—. "Portfolio." Ms. (March 1978) 14-15.

hooks, bell. Teaching to Transgress: Education as the Practice of Freedom. New York: Routledge, 1994.

Humphreys, Julian, and Dawn Martin, eds. Inspiring Education: A Legacy of Learning 1907-2007 - Celebrating 100 Years of Studies in Education at the University of Toronto. Toronto: OISE/UT, 2006. Accessed Aug 13, 2015, https://www.oise.utoronto.ca/oise/UserFiles/CENT\%20PUB_15_10_06.pdf

Kroløkke, Charlotte. "Three Waves of Feminism: From Suffragettes to Grrls." In Gender Communication Theories \& Analyses: From Silence to Performance, 1-23. Thousand Oaks, CA: Sage Publications, 2006. 
Mallon, Mary. “Photography at Spence Bay, N.W.T.” Focus Magazine (1975): 90-93.

Marks, Don. "What's in a Name: Indian, Native, Aboriginal or Indigenous?" $C B C$ News, October 2, 2014. http:/www.cbc.ca/news/canada/manitoba/what-s-in-a-nameindian-native-aboriginal-or- indigenous-1.2784518.

Payne, Carol. The Official Picture: The National Film Board of Canada's Still Photography Division and The Image of Canada, 1941-1971. Montreal: McGill-Queen's University Press, 2013.

—. "Through a Canadian Lens: Discourses on Nationalism and Aboriginal Representation in Governmental Photographs." In Canadian Cultural Poesis: Essays on Canadian Culture. Edited by Garry Sherbert, Annie Gérin, and Sheila Petty, 421-42. Waterloo, ON: Wilfred Laurier University Press, 2006.

-. "'You Can Hear It in Their Voice': Photographs and Cultural Consolidation Among Inuit Youths and Elders." In Oral History and Photography, edited by Alexander Freund and Allistair Thomson, 97-114. New York: Palgrave Macmillan, 2012.

-, and Andrea Kunard, eds. The Cultural Work of Photography in Canada. Montreal: McGill-Queen's University Press, 2011.

- , and Jeffrey Thomas. "Aboriginal Interventions into the Photographic Archives: A Dialogue between Carol Payne and Jeffrey Thomas." Visual Resources 18, no. 2 (January 2002): 109-25.

—, Sheena Ellison and Amos Hayes. "Mapping Views from the North: Cybercartographic Technology and Intuit Photographic Encounters." In Developments in the Theory and Practice of Cybercartography: Applications and Indigenous Mapping, edited by Taylor, D.R. Fraser, 191-200. Amsterdam: Elsevier, 2003.

Paechter, Carrie F. Educating the Other: Gender, Power, and Schooling. London: Falmer Press, 1998.

Repo, Marjaleena. "Photography and the Powerless." This Magazine is About Schools 4, no. 1 (Winter 1970): 130-136.

Ross, W. Gillies. "The Use and Misuse of Historical Photographs: A Case Study from Hudson Bay, Canada." Arctic Anthropology 27, no. 2 (1990): 93-112.

Ruby, Jay. Picturing Culture: Explorations of Film and Culture. Chicago: University of Chicago Press, 2000.

Savard, Dan. Images from the Likeness House. Victoria B.C.: Royal BC Museum, 2010. 
Shrewsbury, Carolyn M. "What is Feminist Pedagogy?" Women's Studies Quarterly 25, no. 1/2 (Summer 1997): 166-73.

Stern, Pamela, and Lisa Stevenson, eds. Critical Inuit Studies: An Anthropology of Contemporary Arctic Ethnography. Lincoln, NE: University of Nebraska Press, 2006.

Szarkowski, John. Mirrors and Windows: American Photography since 1960. NY: The Museum of Modern Art, 1978.

Thomas, Jeff. "From the Collections: The Portfolio: Luminance-Aboriginal Photographic Portraits." The Archivist, no. 112 (1996): 7-23.

Trott, Christopher G. "The Dialectics of 'Us' and 'Other': Anglican Missionary Photographs of the Inuit." The American Review of Canadian Studies 31, no. 1-2 (June 2001): 171-190.

Walters, Margaret. "Second-Wave Feminism: The Late 20th Century." In Feminism: A Very Short Introduction, 97-116. Oxford: Oxford University Press, 2005.

White, Donny. "In Search of Geraldine Moodie: A Project in Progress." In Imaging the Arctic. Edited by J.C.H. King and Henrietta Lidchi, 88-97. Seattle: University of Washington Press, 1998.

Wilford, Nigel. "Spence Bay: Whalebone Carvings." North/Nord (March/April 1974): 22-31. 